\title{
Input Frequency and Word Truncation in Child Japanese: Structural and Lexical Effects
}

\section{Mitsuhiko Ota}

\author{
University of Edinburgh, Edinburgh, U.K.
}

\section{Key words}

early production

input frequency

phonological

development

truncation

\section{Abstract}

Recent research indicates that the statistical properties of the input have an impact on the prosodic shape of young children's word production. However, it is still not clear whether the effects of input statistics emerge from the frequency of prosodic structures or the frequency of individual lexical items. This issue is investigated in this study by analyzing cases of word truncation spontaneously produced by three Japanese-speaking children $(1 ; 5-2 ; 1)$ and the frequencies of relevant words and prosodic word structures produced by their mothers. A significant correlation was found between children's truncation rates for individual target words and the frequency of the same words in the maternal input, but not between the truncation rates for different prosodic word structures and the frequencies of the corresponding structures in maternal speech. The size and shape of truncated outputs were better explained in terms of their correspondence to the target structures than the frequencies of shorter forms in the input. The results indicate that variation in early word truncation is systematically related at least to the lexical frequency of the target words, and that input frequency has a clearer connection to what truncates than how it truncates.

\section{Introduction}

During the earliest stages of linguistic production, children tend to omit syllables from multisyllabic words. Although the details of this phenomenon are quite complex, several general patterns have been identified in previous research. For instance, unstressed syllables are usually more susceptible to omission (Allen \& Hawkins, 1980; Blasdell \& Jensen, 1970; Echols \& Newport, 1992; Wijnen, Krikhaar, \& den Os, 1994). The process also tends to reflect the rhythmic properties of the ambient language (Demuth, 1996; Fee, 1995; Fikkert, 1994; Pye, 1992). Thus, in trochaic languages, a

Acknowledgments: I thank Katsura Aoyama, Katherine Demuth, and Helena Taelman for their valuable comments and suggestions. I also appreciate the feedback and discussion provided by the audiences at the University of Edinburgh P-Workshop and the $13^{\text {th }}$ Manchester Phonology Meeting, where earlier versions of this work were presented.

Address for correspondence. Mitsuhiko Ota, School of Philosophy, Psychology and Language Sciences, University of Edinburgh, 14 Buccleuch Place, Edinburgh EH8 9LN, United Kingdom; e-mail: <mits@ling.ed.ac.uk>. 
pretonic syllable is more likely to be omitted than other weak syllables, as can be seen from typical truncation of English trisyllabic words, for example, banána pronounced as [nǽnə]. A variety of mechanisms have been put forward to explain these patterns, some of which appeal to the preservation of stressed and final syllables either due to children's perceptual disposition (Echols, 1993; Echols \& Newport, 1992) or to prioritized structural correspondence between the adult target form and the child output (Kehoe, 1999/2000). Another type of mechanism that has been proposed is a prosodic template, which, at least for English, consists of a strong syllable followed by an optional weak syllable (Gerken, 1994) or, more generally across languages, a single binary foot (Demuth \& Fee, 1995; Fikkert, 1994; Pater, 1997). The hypothesis is that children's early word outputs are forced to fit such a template, resulting in the truncation of target words with a size or shape that falls outside the prescribed structure. ${ }^{1}$

Although these mechanisms capture the general tendencies in children's early word truncation, they do not provide a straightforward explanation for one important aspect of the phenomenon: the amount of variability seen in word truncation, both across and within languages. Crosslinguistically, it has been observed that children acquiring languages such as Spanish, Japanese and Finnish begin to produce multisyllabic words without truncation earlier than children acquiring languages such as English, German and Dutch (Gennari \& Demuth, 1997; Lleó, 2001; Lleó \& Demuth, 1999; Savinainen-Makkonen, 2000; Vihman, 1991). Lleó and Demuth (1999), for instance, note that the Spanish-speaking children in their study produced trisyllabic outputs such as zapata 'shoe' (sample child production: [pa'pato]) as early as $1 ; 7-1 ; 10,{ }^{2}$ while German-speaking children of the same age rarely produced trisyllabic words without omitting syllables. Some of the Finnish-speaking children studied in Savinainen-Makkonen (2000) were able to produce four-syllable targets without truncation from age 1;7-1;9. This is in striking contrast with the case of English-speaking children, some of whom continue to omit unstressed syllables from trisyllabic words after 2;10 (Kehoe, 1999/2000).

The accounts mentioned above suggest that multisyllabic target words that do not have a certain prosodic profile should be uniformly subjected to truncation until the children overcome such a stage. This does not seem to be the case, however. A quick survey of the literature shows that truncation rates are not consistent across lexical items sharing the same prosodic structure. For example, Taelman and Gillis (2002) report that between 1;10 and 1;11 their Dutch-speaking subject truncated around 33\% of trisyllabic targets with initial secondary stress and final primary stress (swS). The examples below show that trisyllabic words which are presumed to have the same prosodic structure may still variably truncate to monosyllabic or disyllabic outputs, or do not undergo truncation at all.

1 It should be noted that in Gerken's (1994) model, the output is not limited to a single strongweak template, but any structure that can be formed by a sequence of such trochees.

2 Child age is given in 'years;months.days'. For example, 1;6.15 indicates one year, six months and 15 days. 
(1) Maa's variable outputs for swS-words at 1;10.10 (Taelman \& Gillis, 2002) ${ }^{3}$
a. /ssntər'klas/ [sinəkas] 'name'
b. /kolar'yol/ [kJkol] 'name'
c. /telə'fon/ [fon] 'telephone'

The source of this type of variability may lie in subtle differences in the prosodic or segmental composition of the target words, but potential differences in the target structures cannot explain intraword variability, which pervades early spontaneous speech (Demuth, 1996; Macken, 1979). Taelman and Gillis (2002) estimate that 41\% of the word types in their corpus of a Dutch-speaking child had variable output forms. One dramatic demonstration of such variability can be seen in the child's productions of the name Dominiek/domi'nik/, which had six different realizations during one recording session: [domə'nik], [dom'nik], ['mik], [ə'mik], [mə'nik], [də'nik] (Taelman, 2004, p. 198).

Yet another type of variation that cannot result from dissimilarities in the target word is the variable output forms found across individuals in their production of early words (Ferguson \& Farwell, 1975; Stites, Demuth, \& Kirk, 2004). One example from child German $(1 ; 5-1 ; 7)$ is the two distinct ways in which target words containing a schwa are treated (Kehoe \& Lléo, 2003). Some children delete the schwa (e.g., Sonne /'zonə/ $\rightarrow$ [nan:] 'sun') but others opt to reduplicate the stressed vowel (e.g., Jacke /'jakə/ $\rightarrow$ ['jaja] 'jacket').

While some of the variability found in truncation may be attributable to free variation in children's performance, there is a possibility that it is also systematically related to the statistical properties of the ambient language. This link is apparent in the case of crosslinguistic differences. The languages in which truncation of multisyllabic words is developmentally prolonged (e.g., English) have a smaller proportion of multisyllabic target words in child-directed speech than others (e.g., Spanish). According to an estimate by Roark and Demuth (2000), words longer than two syllables constitute less than $10 \%$ of the token-count proportion in child-directed English, whereas they account for nearly a third of the input in child-directed Spanish. Omission of weak initial syllables, a frequent process in children acquiring trochaic languages, fades rapidly at 1;9-1;10 in Spanish (Lléo, 2001), but continues after age two in English (Gerken, 1994), reflecting the different proportions of child-directed words with weak initial syllables between Spanish (45\%) and English (10\%) (Roark \& Demuth, 2000). In early child French, many disyllabic and trisyllabic words truncate to monomoraic forms, for example, tablier [je] 'apron', déshabille [bi] 'undress' (Demuth \& Johnson, 2003), while this pattern is uncommon in child Japanese (Ota, 2003). Demuth and Johnson (2003) attribute this difference to the relatively high frequency of CV words (28\%) found in child-directed French.

One can ask whether the same principle may lie behind intraspeaker and interspeaker variation in truncation. In other words, for any given learner, are words and

3 In describing children's production patterns, I adopt the convention of showing the adult form between slashes and the child form between brackets. 
prosodic word structures that are frequent in the input more likely to be produced without truncation? Although this question has not been thoroughly investigated, research on other areas of phonological development suggests that it is a plausible hypothesis. A number of studies show that the likelihood that a child produces a target phonological structure without modification is related to the input frequency of phonemes, phoneme sequences, and syllable structures. For instance, the accuracy and acquisition timing of phonemes are shown to reflect the frequency in the target language (Beckman, Yoneyama, \& Edwards, 2003; Ingram, 1988; Pye, Ingram, \& List, 1987). More frequent codas are produced earlier than infrequent ones (Stoel-Gammon, 1998), and coda consonants in nonwords are more likely to be reproduced by young children $(1 ; 8-2 ; 4)$ when the phonotactic probability involving the coda consonant is higher (Zamuner, Gerken, \& Hammond, 2004; see also Beckman \& Edwards, 2000, and Munson, 2001, for related results on the effects of input phonotactics for older children). The emergence order of syllable types in Dutch - first CV, then CVC, and finally $\mathrm{VC}$ and $\mathrm{V}$ - also corresponds to the frequencies of different syllable types in child-directed Dutch (Levelt, Schiller, \& Levelt, 1999/2000). These studies all suggest that the frequency of word forms that children hear are likely to influence which word structures will be truncated, and the resulting structures that these truncations will take.

There are different ways in which the prosodic structure of early word production may be related to input frequency. One possibility is that the development of the phonological grammar that underlies children's production is influenced by the distribution of prosodic structures in the input. More frequent exposure to certain structures may motivate grammatical changes that will license those structures if they are not allowed by the current state of the grammar, a process that leads to the early emergence of frequent prosodic structures within a language (Levelt et al., 1999/2000; Levelt \& van de Vijver, 2004), and across languages (Demuth \& Johnson, 2003; Roark \& Demuth, 2000). Similarly, learners may be keeping track of the (co-)occurrence probabilities of different phonological elements (e.g., phonemes, phonotactics, syllables) as part of their phonological knowledge (Aslin, Saffran, \& Newport, 1998). The likelihood of producing a targetlike structure may therefore be dependent on the child's current assessment of the probability of the structural composition of the intended output. These accounts take phonological structures as the variables that mediate frequency distribution and children's production. Applied to the case of word truncation, they predict that children will be more likely to be able to produce (hence less likely to truncate) words that have prosodic word structures that are more frequent in the language.

Frequency effects mediated by prosodic structure may play another role in word truncation. If input frequency influences the types of structure that are considered well-formed according to the current grammar, it may also affect the shape and size of the truncated words (Demuth, 1996; Demuth \& Johnson, 2003). A simple prediction to follow is that the outputs of truncated forms should tend to have prosodic word structures that are more frequent in the input.

An alternative way in which frequency can affect word truncation, albeit not one that is mutually exclusive with the prosodic structure mediation account, is that children's word production reflects the frequency of the individual target words 
attempted. It may be that children are able to construct more stable lexical representations for frequently heard words which can then be accessed with increased accuracy (Beckman \& Edwards, 2000; Storkel \& Gierut, 2002). If these better-learned words share certain structural properties, those properties will tend to appear sooner and more frequently in production. Thus a lexically-mediated frequency effect would make it more likely that children would not truncate high frequency words.

The purpose of this study was to examine both the frequency effects of prosodic word structures and lexical items on children's patterns of early word truncation. More specifically, three questions were addressed: (a) Are words with prosodic structures more frequent in the input less susceptible to truncation? (b) Are target words more frequent in the input less susceptible to truncation? (c) Does word truncation lead to prosodic word structures that are more frequent in the input? These questions were investigated using truncation data in child Japanese. The benefits of using data from Japanese come from the fact that child Japanese generally contains more multisyllabic target words than their English or French counterparts (Vihman, 1991), but also more disyllabic than trisyllabic targets (Ota, 2003). The higher proportion of longer targets offers a wider range of data to examine the relationship between word truncation and input frequency, while the bias toward disyllabic words suggests that, if input frequency plays a role in early word truncation, it will differentiate disyllabic from trisyllabic targets to a larger extent than in a language that has a more even distribution between disyllabic and trisyllabic targets, for example, Spanish (Roark \& Demuth, 2000). The relevant background information on Japanese prosodic structure and child Japanese production is provided in the following section.

\section{The prosodic structure of Japanese and its development}

Japanese has a duration contrast between short and long vowel (e.g., /to/ 'door' vs. /to:/ 'tower') and between singleton and geminate consonant (e.g., /saka/ 'slope' vs. /sakka/ 'writer'). The language also has a lexical pitch accent system. Unlike stress accent, which can manifest as greater duration, spectral tilt and intensity of the accented syllable, the only reliable phonetic correlate of the pitch accent is the movement in pitch (a high-low contour from the accented position). The location of the accent is lexically determined, with each item assigned either one or no accented syllable. ${ }^{4}$ The syllable structure of the language is fairly simple. No clusters are allowed either as onsets or codas. ${ }^{5}$ The only nongeminate coda is a nasal, which is homorganic in place to the onset of the following syllable when there is one (e.g., /tombo/ 'dragonfly',

4 In the Japanese examples cited hereafter, the accented syllable is marked by an acute diacritic accent (except when the coding scheme explained later is used). For example, /háji/ 'chopstick' has an accent on the first syllable (the pitch drops between the first and the second syllable), while /haji/ 'edge' has no accent (there is no pitch fall from the first or second syllable).

5 I adopt the analysis that obstruent onsets that involve palatal sounds, sometimes transcribed as [cj] (e.g., [kja], [pja]), are palatalized singleton onsets, that is, $/ \mathrm{k}^{\mathrm{j}} \mathrm{a} /, / \mathrm{p}^{\mathrm{j}} \mathrm{a} /$ (see Itô \& Mester, 1989). 
/renga/ 'brick') but otherwise "placeless," or weakly closed with a variable point of articulation (Vance, 1987). In addition to a short vowel or a long single vowel, the nucleus can contain a diphthong (e.g., /ai//ou//oi/). A basic inventory of syllables in Japanese is given in Figure 1 along with the standard analysis of their internal structure in moraic theoretic terms.

\section{Figure 1}

Inventory of Japanese syllables

a.

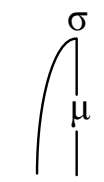

(C) $\mathrm{V}$ b.

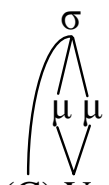

(C) V c.

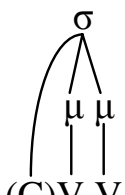

d.

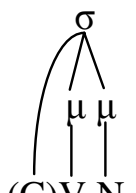

e.

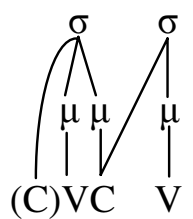

/to/ 'door' /to:/ 'tower' /kai/ 'seashell' /mon/ 'gate' /sakka/ 'writer'

The grouping of the syllable types in (b) through (e) in Figure 1 as bimoraic (or "heavy") syllables, as opposed to the monomoraic (or "light") syllable in (a), has been motivated by a number of morphological operations with prosodic templates, which consistently treat the heavy syllable as equivalent to two light syllables in phonological size (Itô, 1990; Itô \& Mester, 1993; Mester, 1990; Poser, 1990).

The same morphological operations also provide evidence that Japanese has a bimoraic foot structure (Itô, 1990; Mester, 1990; Poser, 1990). Underived lexical items in the Eastern dialects (including Tokyo and Nagoya) are not subjected to a word minimality constraint, as evident in the presence of monomoraic lexical words (e.g., /me/ 'eye', /te/ 'hand', /ha/ 'tooth', /ki/ 'tree', and /e/ 'picture'). However, words that have undergone morphological derivation, such as stems for affixation and reduplication, must be at least two moras long. Such patterns show that in Japanese a bimoraic word is the minimal word, that is, a prosodic word containing nothing but a single foot (McCarthy \& Prince, 1995).

Interestingly, one-year-old Japanese-speaking children show a tendency to lengthen the vowel in monomoraic lexical words: for example, /me/ $\rightarrow$ [me:] 'eye', /te/ $\rightarrow$ [te:] 'hand' (Kawakami \& Ito, 1999; Ota, 2003). This pattern can be taken as support for the hypothesis that early word production conforms to the size of the minimal word (e.g., Demuth, 1995, 1996; Demuth \& Fee, 1995; Pater, 1997). Under this view, the augmentation in production is induced by avoidance of a subminimal prosodic word below the size of two moras. On the other hand, there is little evidence that a bimoraic size upper-bound is imposed on early production in Japanese. Disyllabic structures larger than two moras are among the first words that Japanese-speaking children produce: for example, [baibai] 'bye-bye' $(0 ; 8)$ (Fujiwara, 1977); [mamma] 'food' $(0 ; 10)$ (Noji, 1974). Rather, the gap in truncation rates is found between disyllabic and trisyllabic words. In Ota's (2003) data of spontaneous speech from four children $(1 ; 6-2 ; 0)$, disyllabic words - bimoraic, trimoraic, or quadrimoraic - never reached a truncation rate higher than $10 \%$, while words with three or more syllables 
truncated at a much higher rate, around $100 \%$ when children began to attempt those words. Ota (2003) argues that these findings can be subsumed under the interpretation that early words in child Japanese are minimally and maximally the size of a single foot. But rather than the language-specific bimoraic foot, the relevant foot at this stage is thought to be a more general binary structure that can be either bimoraic or disyllabic, as illustrated in (2).

(2) Early Japanese prosodic words (Ota, 2003)
a. $\operatorname{PrWd}\left[\mathrm{Ft}\left(\sigma_{\mu \mu}\right)\right]$
b. $\operatorname{PrWd}[\mathrm{Ft}(\sigma \sigma)]$

However, an alternative explanation is suggested by several other aspects of the same data. First, the children's target words were predominantly disyllabic (50\%-90\% depending on the child and age). Second, there was a noticeable degree of variability in the truncation rates of words longer than two syllables. At age 1;9-1;10, for example, three out of the four children truncated trisyllabic targets $50.0 \%, 42.1 \%$, and $24.2 \%$ of the time, respectively. However, no obvious patterns common to all children could be found as to which of the trisyllabic targets were more likely to truncate. Third, two of the children frequently truncated a disyllabic word with a light initial syllable and an accented second syllable into a heavy monosyllable (e.g., /takái/ $\rightarrow$ [ta:] 'high', /itái/ $\rightarrow$ [dai] 'ouch'), but this truncation pattern was not found in the other two children. One possible way to account for these findings is that the distribution of prosodic word structures in the input has an effect on truncation patterns. The proportion of disyllabic words in child-directed Japanese may be very high, and that of longer words much smaller, but to various degrees, leading to the generally low rates of truncation for disyllabic targets and high and variable rates of truncation for longer words. Even among disyllabic words, those with prosodic structures such as /takái/ may be much less frequent for some (but not all) children, making them more vulnerable to truncation.

To examine these links, this study compared truncation rates of words and word structures in children speaking Japanese, with the input distribution in the maternal speech that was addressed to the child in child-mother interactions. Although maternal speech in this context is not the only source of linguistic input to the child, it was considered a reasonably representative sample of the ambient language.

\section{Method}

\section{1}

\section{Data and subjects}

The data consisted of spontaneous speech collected by Miyata $(1992,1995,2000)$ from three Japanese-speaking male children, Aki, Ryo and Tai, and their mothers. All three corpora were accessed through the CHILDES database (MacWhinney, 2000). The children were recorded in their homes at weekly intervals, except for Aki's recordings between 1;5 and 1;11, which were conducted at monthly intervals. Each recording session lasted approximately 30 mins. Most of the interactions took place between the child and his mother, although they also involved the researcher, and occasionally, other members of the family. Data transcription was carried out by Miyata, 
mainly using the phonemic JCHAT system (Miyata \& Naka, 1998; Oshima-Takane \& MacWhinney, 1998), but also the broad phonetic UNIBET system when the child's production deviated largely from the adult targets. In the child form examples given below, these transcriptions were converted to IPA notations. No pitch information was included in the transcription. To check the reliability of the transcription, a phonetically-trained native Japanese speaker transcribed 1,000 utterances randomly selected from Tai's recording, which was also available from CHILDES. Between the two transcripts, the target words assigned to the child forms agreed in $95.7 \%$ of the cases. Of the corresponding child forms, $97.3 \%$ had the same number of syllables, and $94.6 \%$ the same short versus long values for vowels and consonants.

The portion of files used for the analysis covered the age period between 1;5 (when the earliest recording was made for Aki and Tai) and 2;1. The mean length of utterance at 1;5 was 1.0 for Aki and Tai, and 1.21 for Tai. At 2;1, it was 1.08 for Aki, 1.37 for Ryo and 2.23 for Tai.

\section{2}

\section{Items analyzed}

Several types of items were excluded from both the truncation analysis and adult input analysis. Words with uncertain targets and those uttered during a conversational overlap were not used. Also excluded were onomatopoeic expressions because it was difficult to ascertain whether repeated onomatopoeic phrases constituted single or multiple prosodic words (e.g., /banbanban/ 'bang bang bang' /amuamuamu/ 'yum yum yum...').

As the focus here was on prosodic structural phenomena, the analysis of the child data did not include target words that contained segments that are intrinsically susceptible to deletion, since these were likely to be truncated for reasons not directly related to their prosodic shape or size. The first of these were words that contained devoiced vowels, which are frequently omitted in early production presumably due to their low perceptual salience or children's imperfect articulatory mastery of devoicing (Ota, 2003). Any low-toned high vowel (/i/ or /u/) between two voiceless obstruents, or in a word-final position after a voiceless obstruent was considered a potential site for devoicing. This definition was a slight oversimplification of the complex conditions of vowel devoicing in Japanese, but it eliminated most obvious cases of truncation that are induced by devoicing, for example, /dékịta/ $\rightarrow$ [det:a] 'it's done', /çikóski/ $\rightarrow$ [ko:ki] 'airplane'. ${ }^{6}$ The second class of words discarded were target words with a flap between homorganic vowels, where homorganic meant either identical (e.g., the two /e/s in /terebi/ 'TV') or agreeing in backness (e.g., the /o/ and /u/ in /oru/ 'fold'). Flaps are frequently omitted in early Japanese production, often resulting in reduction of syllable count (e.g., /terebi/ $\rightarrow$ [te:bi], /orw/ $\rightarrow$ /ow/) (Ota, 2003). This also occurs when flaps are flanked by nonhomorganic vowels, but these cases were included since the assignment of syllable boundary in the child form was fairly straightforward (e.g., /kore/ $\rightarrow$ [ko.e] 'this').

6 For more detailed accounts of vowel devoicing in Japanese, see Vance (1987) and Tsuchida (2001). 
The analysis of truncation was conducted only on target words with two or more syllables. After the elimination of the forms described above, the total number of nonmonosyllabic word types/tokens analyzed in the study was 193/922 for Aki, $209 / 2641$ for Ryo and $864 / 11434$ for Tai. These accounted for $80.3 \%$ and $85.5 \%$ of the total data in type count and token count respectively.

\section{3}

\section{Prosodic analysis and coding}

For the prosodic analysis, a word was defined as the smallest grammatical unit that could constitute a free-standing utterance, which is also the minimal unit that could form an accentual phrase (a prosodic phrase with maximally one pitch accent). In Japanese, nouns and demonstrative pronouns are free morphemes that can occur independently of nominal bound morphemes such as case markers and postpositions, but verb and adjective roots must occur with inflectional morphemes, such as the tense marker. Thus, nouns were analyzed in their bare forms but verbs and adjectives were analyzed in their affixed forms. The units analyzed roughly corresponded to children's one-word utterances, which typically comprised a noun (tori 'bird'), a demonstrative pronoun (are 'that'), a verbal complex (tabe-ta 'eat-PAST') or an adjectival complex (ooki-i 'big-NONPAST').

All such units as "target words," either produced by the mother or attempted by the child, were analyzed in terms of three parameters: (a) the number of syllables; (b) the weight of each syllable; and (c) the location of pitch accent. Syllabification and weight assignment followed the standard assumptions of Japanese syllables described above. The vowel sequences /ai/, /oi/, and /ou/ were treated as diphthongs but other vowel sequences were considered to be heterosyllabic. Syllables were analyzed as light ('L') when the rime only contained a short vowel (see (a) in Figure 1), and heavy (' $\mathrm{H}$ ') when the rime contained a long vowel, a diphthong, or a coda, including the first half of a geminate (see (b)-(e) in Figure 1). The location of the accent was marked by using a number matching the position of the accentbearing syllable, for example, ' 1 ' = first syllable, ' 2 ' = second syllable. Words with no lexical accent were coded as ' 0 '. Some examples of the prosodic analysis and coding are given in (3).

(3) Examples of prosodic coding
a. /dekkái/
'huge':
$\mathrm{HH} 2$
b. /tábe-ta/
'eat-PAST':
LLL1
c. /urgoká-nai/ 'move-NEG':
LLLH3
d. /unténfu//
'driver':
HHL2
e. /budo:/ 'grape':
LH0

The location of the accent was first determined according to the standard dialect, even though the children's families lived in Nagoya, a city approximately $300 \mathrm{~km}$ away from Tokyo where the standard dialect is spoken. Despite the distance, dialectal comparison shows that Nagoya and Tokyo belong to the same regional accent zone 
and share the basic properties of lexical accent (Hirayama, 1985). According to a nation-wide survey carried out by Sugito (1997), approximately $90 \%$ of word phrases produced by middle-aged speakers from Nagoya had the same pitch contours as those produced by speakers from Tokyo. One notable prosodic difference between Nagoya and Tokyo is the delayed phrase-initial rise sometimes observed in the former. ${ }^{7}$ However, this is an intonational feature that applies systematically to phrases, and because the focus of this study was on lexical prosody, this dialectal difference was not taken into consideration in the coding. To identify any lexical differences, a speaker of standard Japanese listened to the speech of Tai's mother and marked words that systematically had a different accent location. These words (a total of 8 items) were removed from the analysis.

Since the transcriptions did not indicate the presence or locations of pitch accent, children's productions were only analyzed for the number of syllables and their weight. If the number of syllables produced was fewer than that of the target, the production was considered truncated. If the number of syllables matched that of the target, the production was treated as a nontruncated output regardless of the syllable structure or the segmental composition.

\section{Analyses}

The analyses proceeded as follows. Analysis 1 served as a preparatory analysis in which truncation rates of different word sizes were compared with the overall input distribution in the maternal speech. Analysis 2 addressed the question of whether truncation rates in children's word production vary as a function of the frequencies of prosodic word structures in the input. Analysis 3 tested whether truncation rates vary as a function of the frequency of the target words in the input. Analysis 4 examined whether truncated words tend to become prosodic structures that are frequent in the input.

\section{1}

\section{Analysis 1: Target word size, truncation, and input frequency}

The first analysis looked at the overall pattern of truncation and input frequency in terms of word size. The purpose was to obtain an overview of the global truncation pattern and to examine whether the truncation rates across different word sizes were consistent with the input distribution. Children's truncation rates were calculated for target structures classified into four broad categories: (a) words with two syllables and two moras (i.e., LL, e.g., /koko/ 'here'), (b) words with two syllables and three or four moras (i.e., HL, LH or HH, e.g., /kákka/ 'mom', /budo:/ 'grape', /o:kí/ / big'), (c) words with three syllables (e.g., /bánana/ 'banana'), and (d) words with four or more syllables (e.g., /uggokánai/ '(it)doesn't move'). Truncation rates were obtained

7 In both Tokyo and Nagoya, a phrase boundary is marked by a low pitch, which rises during the phrase. In Tokyo, this rise typically occurs between the first and second mora, while in Nagoya, it occurs between the second and third mora when the phrase-initial word is longer than two moras. 
by dividing the tokens of truncated forms by the number of attempts made at target words in each category. The data were grouped into periods of three months: $1 ; 5-1 ; 7$, $1 ; 8-1 ; 10$ and $1 ; 11-2 ; 1$. The results of this analysis are shown in Tables $1-3$. Truncation rates are given in percentages along with the number of truncated forms and attempts (shown in brackets). Results of chi-square analysis of distribution are reported in the bottom panel of the table.

\section{Table 1}

Aki's truncation rate by target size and age (\%)

\begin{tabular}{llcc}
\hline Number of syllables & $1 ; 5-1 ; 7$ & $1 ; 8-1 ; 10$ & $1 ; 11-2 ; 1$ \\
\hline Two (all) & $4.8(1 / 21)$ & $12.0(9 / 75)$ & $3.1(22 / 705)$ \\
$\quad 5.3(1 / 19)$ & $5.0(1 / 20)$ & $2.4(7 / 292)$ \\
$\quad 3$ or 4 moras & $0.0(0 / 2)$ & $14.5(8 / 55)$ & $3.6(15 / 413)$ \\
Three & $--(0 / 0)$ & $100.0(5 / 5)$ & $47.9(46 / 96)$ \\
Four or more & $--(0 / 0)$ & $--\quad(0 / 0)$ & $85.0(17 / 20)$ \\
\hline Chi-square $(d f=1)$ & & & \\
$2 \sigma / 2 \mu$ versus $3 \sigma$ & $\mathrm{n} / \mathrm{a}$ & $19.79 * * *$ & $126.93 * * *$ \\
$2 \sigma / 3-4 \mu$ versus $3 \sigma$ & $\mathrm{n} / \mathrm{a}$ & $19.72 * * *$ & $144.82 * * *$ \\
$3 \sigma$ versus $4(+) \sigma$ & $\mathrm{n} / \mathrm{a}$ & $\mathrm{n} / \mathrm{a}$ & $9.17 * *$ \\
\hline
\end{tabular}

Note: ${ }^{* *} p<.01,{ }^{* * *} p<.001$

\section{Table 2}

Ryo's truncation rate by target size and age (\%)

\begin{tabular}{|c|c|c|c|}
\hline Number of syllables & $1 ; 5-1 ; 7$ & $1 ; 8-1 ; 10$ & $1 ; 11-2 ; 1$ \\
\hline Two (all) & $0.4(1 / 245)$ & $0.4(3 / 698)$ & $1.9(24 / 1243)$ \\
\hline 2 moras & $1.9(1 / 54)$ & $0.7 \quad(3 / 419)$ & $0.8(5 / 607)$ \\
\hline 3 or 4 moras & $0.0 \quad(0 / 191)$ & $0.0 \quad(0 / 279)$ & $3.0(19 / 636)$ \\
\hline Three & -- $\quad(0 / 0)$ & $59.5 \quad(22 / 37)$ & $10.6(37 / 348)$ \\
\hline Four or more & -- $\quad(0 / 0)$ & $100.0(5 / 5)$ & $49.2(32 / 65)$ \\
\hline \multicolumn{4}{|l|}{ Chi-square $(d f=1)$} \\
\hline $2 \sigma / 2 \mu$ vs. $3 \sigma$ & $\mathrm{n} / \mathrm{a}$ & $226.40 * * *$ & $50.61 * * *$ \\
\hline $2 \sigma / 3-4 \mu$ vs. $3 \sigma$ & $\mathrm{n} / \mathrm{a}$ & $178.31 * * *$ & $24.49 * * *$ \\
\hline $3 \sigma$ versus $4(+) \sigma$ & $\mathrm{n} / \mathrm{a}$ & 3.15, n.s. & $58.64 * * *$ \\
\hline
\end{tabular}

Note: ${ }^{* *} p<.01,{ }^{* * *} p<.001$ 


\section{Table 3}

Tai's truncation rate by target size and age (\%)

\begin{tabular}{lcrc}
\hline Number of syllables & $1 ; 5-1 ; 7$ & $1 ; 8-1 ; 10$ & $1 ; 11-2 ; 1$ \\
\hline Two (all) & $2.4(48 / 2027)$ & $0.1(3 / 2695)$ & $0.2(7 / 4080)$ \\
$\quad 3.5 \quad(47 / 1353)$ & $0.2(3 / 1243)$ & $0.1(2 / 2123)$ \\
$\quad 3$ or 4 moras & $0.0(0 / 191)$ & $0.0(0 / 1455)$ & $0.3(5 / 1957)$ \\
Three & $42.4(109 / 257)$ & $6.8(47 / 688)$ & $0.9(10 / 1060)$ \\
Four or more & $53.8(21 / 39)$ & $24.5(39 / 159)$ & $11.4(49 / 429)$ \\
\hline Chi-squareare $(d f=1)$ & $318.97 * * *$ & & $13.58 * * *$ \\
$\quad 2 \sigma / 2 \mu$ vs. $3 \sigma$ & $374.22 * * *$ & $101.63 * * *$ & $6.58 *$ \\
$2 \sigma / 3-4 \mu$ vs. $3 \sigma$ & 1.80, n.s. & $44.34 * * *$ & $88.12 * * *$ \\
$3 \sigma$ versus $4(+) \sigma$ & & & \\
\hline$N$
\end{tabular}

Note: $* p<.05,{ }^{* * *} p<.001$

Although there are some differences across the children in the timing of development, several common patterns are observable in the truncation pattern. Truncation rates are consistently lower for disyllabic targets than for trisyllabic targets whether they are bimoraic or longer. This confirms Ota's (2003) finding that there is a clear difference between disyllables and trisyllables in their tendency to truncate, while the number of moras in the disyllabic targets is not related to truncation rates. But, where enough data are available, a difference is also detected between targets with three syllables and targets with four or more syllables. This order of truncation rates corresponds to the order of first recorded attempts at different word sizes. Although target words in all four categories appeared in Tai's earliest month of recording $(1 ; 5)$, production of disyllabic targets preceded the first recorded attempts at trisyllabic targets for both Aki and Ryo (at 1;10 and 1;8, respectively), which in turn occurred before the first documented targets with four or more syllables (at $2 ; 0$ and $1 ; 10$, respectively). As the data are sampled speech, however, we cannot determine whether this sequence of first occurrence reflects the actual order of emergence or the order of frequency in the child's production.

As far as truncation is concerned, then, disyllabic targets tend to truncate less frequently than trisyllabic targets, and trisyllabic targets less frequently than longer targets. To see whether this can be reflective of the input distribution, the maternal speech addressed to the child throughout the period of investigation $(1 ; 5-2 ; 1)$ was analyzed. The proportion of words with different number of syllables was calculated both in terms of the number of times they were produced (token frequency) and the number of different lexical items used (type frequency). Disyllabic words were further classified into those with two moras and those with three or four moras.

The results, reported in Table 4, appear to support the prediction that more frequent prosodic types (as measured in syllable count) are less likely to truncate in Japanese children's word production. Disyllables, which truncate the least, are by far the most frequent word size in the maternal input. Also, consistent with the 
observation that both disyllabic/bimoraic words and disyllabic/triquadrimoraic words truncate less frequently than trisyllabic targets, both are more frequent than trisyllabic words at least in token count. Furthermore, the frequency of multisyllabic words diminishes as a function of length.

\section{Table 4}

Word size frequency in maternal speech: overall percentage (and range) in combined data from three mothers

\begin{tabular}{lrlll}
\hline Number of syllables & Type & \multicolumn{2}{l}{ Token } \\
\hline One & 8.7 & $(8.7-14.0)$ & 28.3 & $(22.8-28.7)$ \\
Two (all) & 37.5 & $(32.1-47.3)$ & 49.2 & $(47.4-52.7)$ \\
$\quad 2$ moras & 22.9 & $(22.1-26.6)$ & 27.0 & $(19.8-29.2)$ \\
$\quad$ or 4 moras & 14.7 & $(12.9-25.2)$ & 22.2 & $(21.5-29.6)$ \\
Three & 31.6 & $(14.6-32.5)$ & 14.8 & $(10.8-14.8)$ \\
Four & 15.5 & $(9.5-16.0)$ & 5.7 & $(5.1-8.3)$ \\
Five & 4.1 & $(1.5-4.2)$ & 1.2 & $(0.9-1.2)$ \\
Six or more & 2.6 & $(0.7-2.8)$ & 0.7 & $(0.3-0.7)$ \\
\hline
\end{tabular}

However, such correspondence between input and truncation can be accidental. Word frequency (at least in adult language) is usually negatively correlated with word length (Zipf, 1935). Therefore, truncation rates can increase with word length for reasons other than frequency and still show a correlation with frequency. Another reason why a simple correspondence at this level needs to be interpreted with caution is the considerable amount of variability seen in the truncation data. Tables 5-7 show the mean, $\mathrm{SD}$, and range of truncation rates for the different target size categories at an age where the overall truncation rates exhibit a pattern matching the order of input frequency for each of the children. With the exception of Aki's data for words with four or more syllables (which is estimated from only 3 word types), the variation in truncation rates for multisyllabic targets is extremely high. This classification based on the number of syllables, therefore, is not only confounded with the relationship between word length and frequency in adult speech, but is also too coarse as a basis for drawing tenable conclusions about the connection between truncation and input frequency. These problems can be circumvented by comparing truncation and input frequency of prosodic structures while controlling for word size. If there is a frequency effect of prosodic structures, even words with a comparable length should show a systematic correlation between their prosodic structures and the corresponding input distribution. This prediction was tested in the next analysis. 


\section{Table 5}

Aki's truncation rates at 2;0

\begin{tabular}{lcccc}
\hline Target size & Mean $(\%)$ & $S D$ & Range & Word types \\
\hline 2 syllables/2 moras & 3 & 11 & $0-50$ & 20 \\
2 syllables/3-4 moras & 6 & 18 & $0-100$ & 44 \\
3 syllables & 44 & 53 & $0-100$ & 9 \\
4 or more syllables & 100 & 0 & 100 & 3 \\
\hline
\end{tabular}

\section{Table 6}

Ryo's truncation rates at 2;0

\begin{tabular}{lcccc}
\hline Target size & Mean $(\%)$ & SD & Range & Word types \\
\hline 2 syllables/2 moras & 0 & 0 & 0 & 15 \\
2 syllables/3-4 moras & 8 & 22 & $0-100$ & 33 \\
3 syllables & 20 & 33 & $0-100$ & 21 \\
4 or more syllables & 75 & 41 & $7-100$ & 5 \\
\hline
\end{tabular}

\section{Table 7}

Tai's truncation rates at $1 ; 8$

\begin{tabular}{lcccc}
\hline Target size & Mean $(\%)$ & SD & Range & Word types \\
\hline 2 syllables/2 moras & 0 & 0 & 0 & 26 \\
2 syllables/3-4 moras & 0 & 0 & 0 & 54 \\
3 syllables & 10 & 25 & $0-100$ & 32 \\
4 or more syllables & 36 & 50 & $0-100$ & 14 \\
\hline
\end{tabular}

\section{2}

\section{Analysis 2: Target prosodic structures, truncation and input frequency}

In this analysis, target words were classified into prosodic structure types defined not only by syllable count, but also by syllable weight and the presence/location of pitch accent. The truncation analysis for children's production was carried out for the three-month period in which the child attempted to produce more than three different prosodic word types with three or more syllables. Because Aki's and Ryo's first two datasets did not meet this criterion, they were not included in the analysis. Tai's third dataset was also excluded because of its very low overall rate of truncation $(1.2 \%)$. The four datasets that were used in the analysis were Aki's 1;11-2;1, Ryo's $1 ; 11-2 ; 1$, Tai's $1 ; 5-1 ; 7$ and Tai's $1 ; 8-1 ; 10$. The classification of the target words into a large number of detailed prosodic word structures resulted in a reduced number of data points in each group. In order to minimize sampling errors and over-representation of a few 
frequent lexical items, only target words that were attempted at least five times were included in the calculation, and the truncation rate for each prosodic structure type was calculated as the mean truncation rate of word types belonging to that category, rather than the token ratio of all truncated attempts. As for the input frequency in the maternal speech, the proportion of words belonging to each prosodic word type was calculated both in terms of token count and type count.

In Table 8, the truncation rates are shown together with the corresponding maternal input in type and token frequency for the most commonly targeted prosodic structures. The full descriptive results are given in the Appendix.

\section{Table 8}

Truncation rates (percentage) and maternal input frequency (percentage type and token) for selected prosodic structures

$\frac{\frac{A k \boldsymbol{i}}{\text { Truncation Input }}}{\text { type token }}$

$\frac{\text { Ryo }^{\text {Truncation }} \text { Input }}{}$

type token

\section{LL0}

LL1

LL2

LH0

LH2

HL1

HH1

LLL1

LLL2

$$
\text { LH }
$$


with truncation rates higher than others. For instance, in Ryo's data, LH2's 13.6\% is comparatively higher than the rates for his other disyllables and in Tai's $1 ; 5-1 ; 7$ data, $\mathrm{LH} 0$ stands out with $100 \%$. Examples of truncation occurring in these prosodic word structures are shown in (4) and (5). Note that it is problematic to ascribe the high truncation rates simply to the general markedness of these structures since Aki does not truncate his LH2 targets (e.g., /takái/ $\rightarrow$ [takai] 'high' $(2 ; 1)$ ), and Ryo does

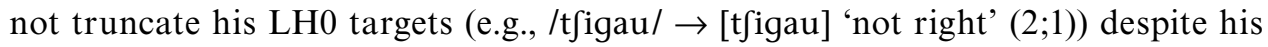
truncation of LH2. As reported in Ota (2003), the truncation patterns of LH targets exhibit individual differences.

(4) Truncation of LH2 in Ryo's data
a. /omói/ $\rightarrow$ [moi] 'heavy' $(2 ; 0.15)$
b. /kajúi/ $\rightarrow$ [juii] 'itchy' $(2 ; 1.4)$
c. /surgói/ $\rightarrow$ [yoi $]$ 'great' $(2 ; 0.8)$

(5) Truncation of LH0 in Tai's data
a. /budo:/ $\rightarrow$ [bur] 'grape' $(1 ; 5.20)$
b. /toke: $/ \rightarrow$ [ke:] 'clock' $(1 ; 6.11)$

Turning to the trisyllabic targets, we notice that some structures have truncation rates lower than other trisyllables attempted by the same child, for instance, Aki's HHH2 (e.g., / /inkánsen/ 'bullet train') with 5.3\%, Ryo's LLL2 (e.g., /hasamu/ 'clip') and HHH2 (e.g., /hambá:ga:/ 'hamburger'), both with $0 \%$, and Tai's HHH1 (e.g., /táifo:kun/ '(Tai's name)') with 14.3\%. Again, there are some discrepancies across individuals. HHH2 has a low rate for a trisyllable in both Aki and Ryo, but a relatively high rate in Tai. Conversely, the rate for $\mathrm{HHH} 1$ is comparatively low in Tai but high in Aki.

The question is whether such variability across structures and individuals is systematically related to the input frequency of words with the same prosodic profile. If it is, we predict that words that have a prosodic structure that is frequent in the individual input are less likely to truncate even when they are controlled for length. To test this prediction, a correlation analysis between the mean truncation rate of each prosodic word structure and the maternal input frequency was carried out separately for disyllabic targets and trisyllabic targets. As the data presented nonuniform variance, both truncation rates and input frequency estimates were log transformed before running the correlation tests. However, words belonging to some prosodic structure types were not truncated at all, producing zero values that could not be log transformed. Two analyses, therefore, were carried out: One between the truncation rate and the maternal input excluding prosodic structures that were never truncated, and one between the nontruncation rate (i.e., the proportion of prosodic structures that were not truncated) and the maternal input excluding structures that were always truncated.

The results, reported in Tables 9 and 10, failed to support the prediction. Table 9 shows no significant correlations between the mean truncation rate of a prosodic structure and its proportional frequency in the maternal input either within the 
disyllabic or trisyllabic data. Similarly, Table 10 shows no significant correlations when the mean nontruncation rate was used instead of the truncation rate. In sum, the variability in truncation rate found within disyllabic targets and trisyllabic targets was not systematically related to the estimated input frequency of prosodic structure types used in the analysis.

\section{Table 9}

Correlation between prosodic type input frequency and truncation rate for disyllabic targets and trisyllabic targets (Pearson's $r$, 2-tailed; all results not significant)

\begin{tabular}{lcccccccc}
\hline & Aki (1;11-2;1) & \multicolumn{2}{c}{$\boldsymbol{R y o}(\mathbf{1 ; 1 1 - 2 ; 1 )}$} & \multicolumn{2}{c}{ Tai (1;5-1;7) } & \multicolumn{2}{c}{ Tai (1;8-1;10) } \\
\cline { 2 - 9 } Input & $\begin{array}{l}\text { Disyll. } \\
(n=7)\end{array}$ & $\begin{array}{l}\text { Trisyll. } \\
(n=3)\end{array}$ & $\begin{array}{l}\text { Disyll. } \\
(n=6)\end{array}$ & $\begin{array}{l}\text { Trisyll. } \\
(n=7)\end{array}$ & $\begin{array}{c}\text { Disyll. } \\
(n=10)\end{array}$ & $\begin{array}{c}\text { Trisyll. } \\
(n=11)\end{array}$ & $\begin{array}{l}\text { Disyll. } \\
(n=6)\end{array}$ & $\begin{array}{l}\text { Trisyll. } \\
(n=9)\end{array}$ \\
\hline Type & .398 & .656 & -.097 & .083 & -.557 & .174 & .308 & .407 \\
Token & .851 & -.982 & -.764 & .387 & -.590 & -.372 & -.397 & .141 \\
\hline
\end{tabular}

\section{Table 10}

Correlation between prosodic type input frequency and nontruncation rate for disyllabic targets and trisyllabic targets (Pearson's $r$, 2-tailed; all results not significant)

\begin{tabular}{|c|c|c|c|c|c|c|c|c|}
\hline \multirow[b]{2}{*}{ Input } & \multicolumn{2}{|c|}{$\operatorname{Aki}(1 ; 11-2 ; 1)$} & \multicolumn{2}{|c|}{$\operatorname{Ryo}(1 ; 11-2 ; 1)$} & \multicolumn{2}{|c|}{$\operatorname{Tai}(1 ; 5-1 ; 7)$} & \multicolumn{2}{|c|}{$\operatorname{Tai}(1 ; 8-1 ; 10)$} \\
\hline & $\begin{array}{l}\text { Disyll. } \\
(n=10)\end{array}$ & $\begin{array}{l}\text { Trisyll. } \\
(n=2)\end{array}$ & $\begin{array}{l}\text { Disyll. } \\
(n=11)\end{array}$ & $\begin{array}{l}\text { Trisyll. } \\
(n=12)\end{array}$ & $\begin{array}{l}\text { Disyll. } \\
(n=10)\end{array}$ & $\begin{array}{l}\text { Trisyll. } \\
(n=11)\end{array}$ & $\begin{array}{l}\text { Disyll. } \\
(n=11)\end{array}$ & $\begin{array}{l}\text { Trisyll. } \\
(n=17)\end{array}$ \\
\hline Type & .011 & -- & -.421 & .279 & -.087 & -.073 & -.290 & -.172 \\
\hline Token & -.305 & -- & -.212 & .310 & -.177 & -.261 & -.119 & -.282 \\
\hline
\end{tabular}

Note: Dashes indicate that the correlation could not be computed due to constant variables

\section{3}

\section{Analysis 3: Target word frequency and truncation}

The purpose of this analysis was to examine whether there is a lexical frequency effect on word truncation. If children are less likely to truncate target words that are more frequent in the input, there should be a negative correlation between truncation rate and word frequency, or a positive correlation between nontruncation rate and word frequency. These predictions were tested separately for disyllabic targets and trisyllabic targets. Truncation rates and nontruncation rates were calculated as the number of truncated and nontruncated outputs divided by the number of attempts made. Frequency in maternal speech was calculated as the proportion of each target word in the total token count of words produced by the mother. All values were log transformed, with words never truncated removed from the truncation analysis and 
words always truncated removed from the nontruncation analysis to avoid zero-value problems with the transformation.

The results reported in Table 11 show a significant negative correlation between lexical frequency and truncation rate in three out of the four disyllabic datasets, and three out of the four trisyllabic datasets. These outcomes support the prediction that words that are more frequent in the input are less likely to truncate.

\section{Table 11}

Correlation between lexical input frequency and truncation rate for disyllabic targets and trisyllabic targets (Pearson's $r$, 2-tailed)

\begin{tabular}{|c|c|c|c|c|c|c|c|}
\hline \multicolumn{2}{|c|}{$\operatorname{Aki}(1 ; 11-2 ; 1)$} & \multicolumn{2}{|c|}{$\operatorname{Ryo}(1 ; 11-2 ; 1)$} & \multicolumn{2}{|c|}{ Tai $(1 ; 5-1 ; 7)$} & \multicolumn{2}{|c|}{ Tai $(1 ; 8-1 ; 10)$} \\
\hline $\begin{array}{l}\text { Disyll. } \\
(n=11)\end{array}$ & $\begin{array}{l}\text { Trisyll. } \\
(n=3)\end{array}$ & $\begin{array}{l}\text { Disyll. } \\
(n=8)\end{array}$ & $\begin{array}{l}\text { Trisyll. } \\
(n=5)\end{array}$ & $\begin{array}{l}\text { Disyll. } \\
(n=14)\end{array}$ & $\begin{array}{l}\text { Trisyll. } \\
(n=8)\end{array}$ & $\begin{array}{l}\text { Disyll. } \\
(n=8)\end{array}$ & $\begin{array}{l}\text { Trisyll. } \\
(n=11)\end{array}$ \\
\hline-.340 & $-.999 *$ & $-.722^{*}$ & -.038 & $-.566^{*}$ & $-.815^{*}$ & $-.550^{*}$ & $-.612^{*}$ \\
\hline
\end{tabular}

Note: $* p<.05$

\section{Table 12}

Correlation between lexical input frequency and nontruncation rate for disyllabic targets and trisyllabic targets (Pearson's $r$, 2-tailed)

\begin{tabular}{|c|c|c|c|c|c|c|c|}
\hline \multicolumn{2}{|c|}{$\operatorname{Aki}(1 ; 11-2 ; 1)$} & \multicolumn{2}{|c|}{$\operatorname{Ryo}(1 ; 11-2 ; 1)$} & \multicolumn{2}{|c|}{ Tai $(1 ; 5-1 ; 7)$} & \multicolumn{2}{|c|}{ Tai $(1 ; 8-1 ; 10)$} \\
\hline $\begin{array}{l}\text { Disyll. } \\
(n=40)\end{array}$ & $\begin{array}{l}\text { Trisyll. } \\
(n=2)\end{array}$ & $\begin{array}{c}\text { Disyll. } \\
(n=33)\end{array}$ & $\begin{array}{l}\text { Trisyll. } \\
(n=15)\end{array}$ & & & & $\begin{array}{c}\text { Trisyll. } \\
(n=30)\end{array}$ \\
\hline & $1.000^{* *}$ & & -.012 & -.054 & -.403 & -.235 & .072 \\
\hline
\end{tabular}

Note: $* p<.05 ; * * p<.01$

However, as revealed in Table 12, these results are not replicated in the analysis of nontruncation contrary to the prediction that there should be a positive correlation between the mean nontruncation rate of a lexical item and its relative frequency in the maternal input. Recall that the difference between the analysis in Table 11 and that in Table 12 is that the former did not include words that were never truncated. The effects of these nontruncated words can be seen in the datasets for which a significant correlation was found in Table 11 but not in Table 12. Two such examples, Ryo's disyllabic targets and Tai's trisyllabic targets at 1;5-1;7, are shown in Figure 2. As evident from these scatterplots, although truncated words tend to have a higher nontruncation rate when they are more frequent in the input, this trend is masked by a large number of words which do not undergo any truncation. There is a general ceiling effect on the nontruncation rate, and the residuals are much larger when the input frequency is low. The generalization is that truncation does not occur frequently, but when it does, it tends to happen more with words that are infrequent in the input. 


\section{Figure 2}

Nontruncation rate per lexical item as a function of input frequency: Ryo's disyllabic targets at 1;11-2;1 (left panel) and Tai's trisyllabic targets at age 1;5-1;7 (right panel)

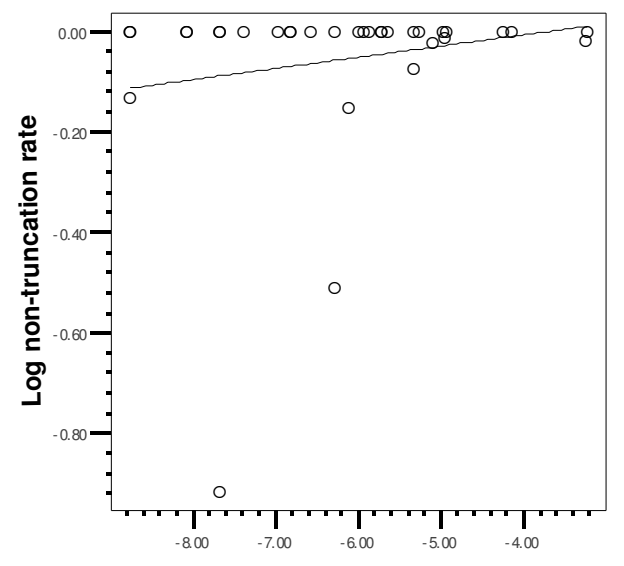

Log lexical frequency in maternal speech

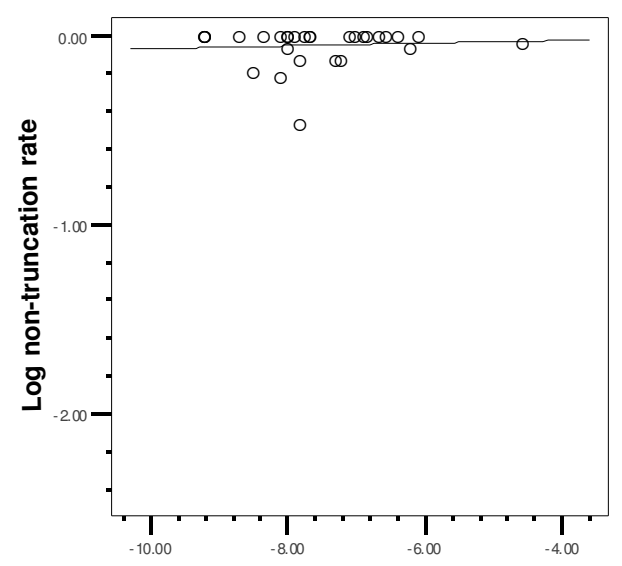

Log lexical frequency in maternal speech

The second half of this generalization can be confirmed by Figures $3-6$, which plot the log truncation rate of each lexical item in the child's production that underwent some truncation, against the log lexical frequency of the same lexical item in the maternal speech. These scatterplots offer some explanations for the rather haphazard pattern that emerged in Table 8, which, according to Analysis 2, was not correlated to structural frequencies in the input. Take Tai's LH0 at 1;5-1;7, for example, which had an uncharacteristically high truncation rate, $100 \%$ (see Table 8). In Analysis 2, this structure was actually represented by only one target word: /toke:/ 'clock' which always truncated to [ke:] (cf. (5)) (the other items were not included due to low number of attempts).

\section{Figure 3}

Truncation rate per lexical item as a function of input frequency (Aki, 1;11-2;1)

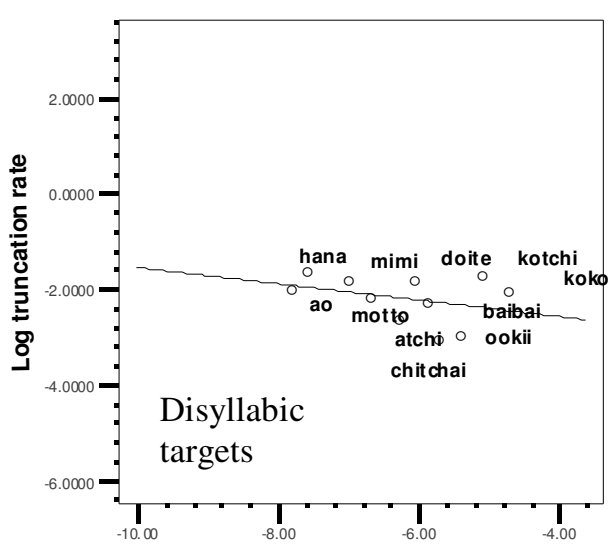

Log lexical frequency in maternal speech

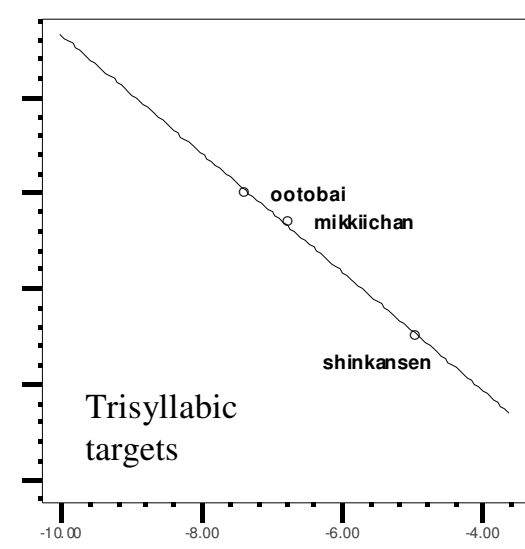

Log lexical frequency in maternal speech 


\section{Figure 4}

Truncation rate per lexical item as a function of input frequency (Ryo, 1;11-2;1)
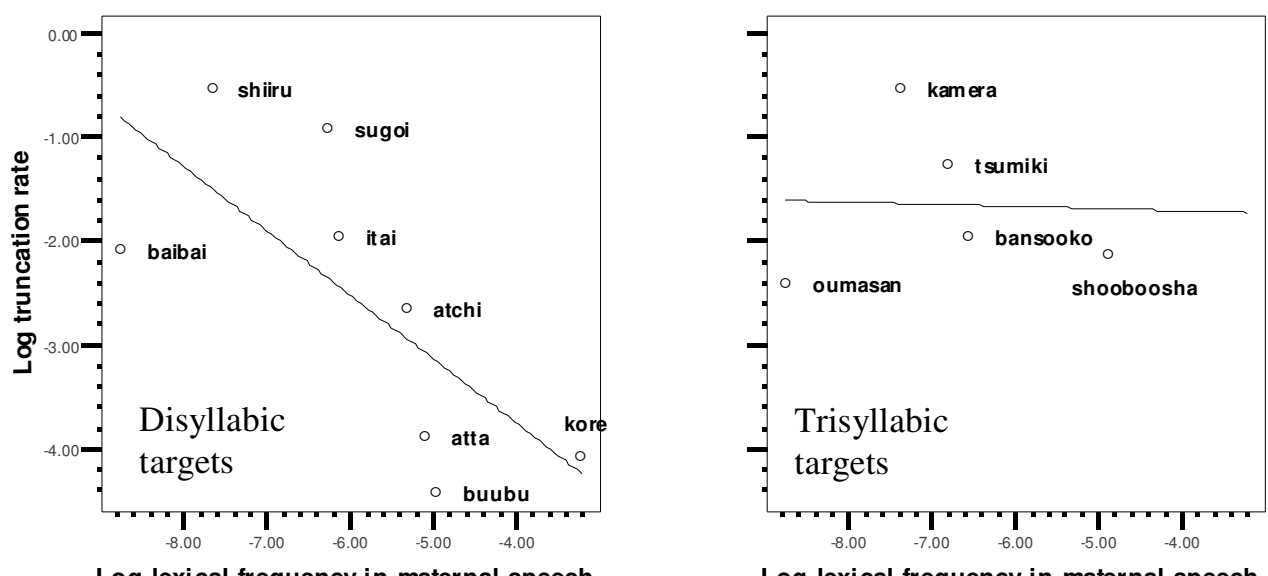

Log lexical frequency in maternal speech

Log lexical frequency in maternal speech

\section{Figure 5}

Truncation rate per lexical item as a function of input frequency (Tai, 1;5-1;7)

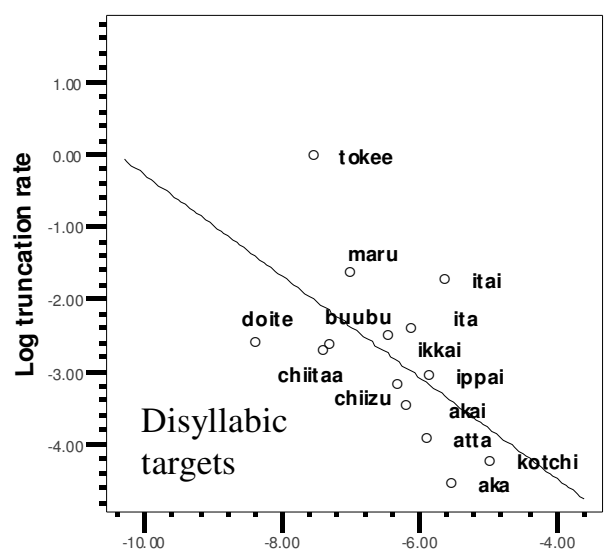

Log lexical frequency in maternal speech

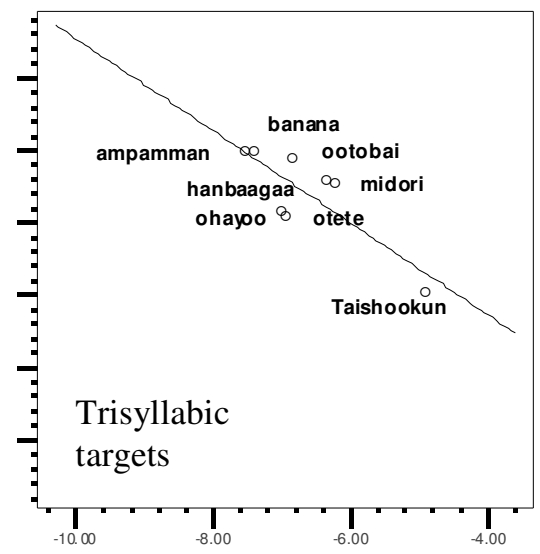

Log lexical frequency in maternal speech

Figure 5 shows that the high truncation rate for this item is systematically related to its low frequency in the input. But this correlation holds only between /toke:/'s truncation rate and its own input frequency, not the input frequency of all LH0 words. Similarly, the reason why Ryo's truncation rate for LH2 as a whole is relatively high is that it includes the frequently truncated word /sugói/ ( $\rightarrow$ [yoi]) 'great' (compare (4)). In lexical terms, the high truncation rate of /sugói/ is predictably related to its low frequency (see Fig. 4).

It is also interesting to note that common lexical items have very comparable frequencies and truncation rates across children. Thus, /itái/ has midfrequency and midtruncation rate in both Ryo (Fig. 4, left panel) and Tai (Fig. 5, left panel), and 


\section{Figure 6}

Truncation rate per lexical item as a function of input frequency (Tai, 1;8-1;10)

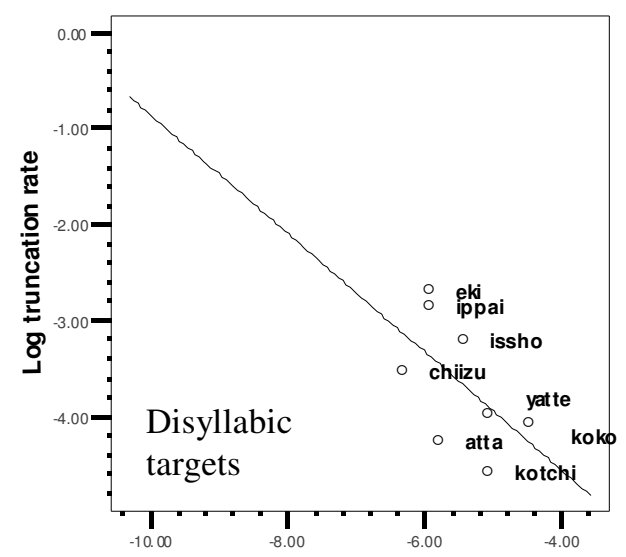

Log lexical frequency in maternal input

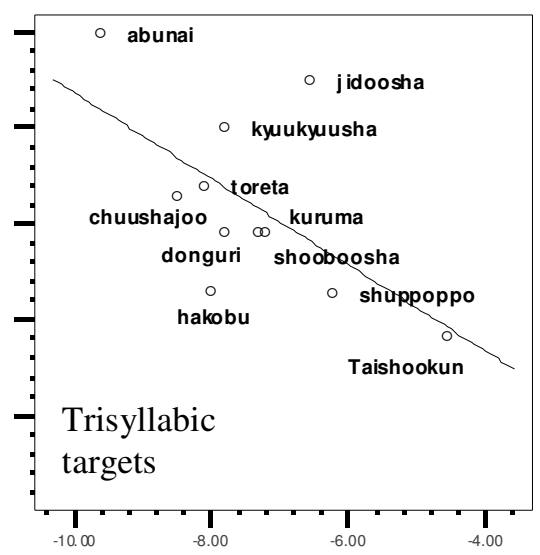

Log lexical frequency in maternal input

látta/ has high frequency and low truncation rate in Ryo (Fig. 4, left panel) and Tai (Figures 5 and 6, left panel). This suggests that the main reason why we find intersubject differences in a structure-based summary such as Table 8 is not because children receive variable input for each word structure but because the composition of their lexicon varies; so for example, one child's pool of LH0 words is different from another's, which can result in differences in their truncation rates for LH0 words.

\section{4}

\section{Analysis 4:}

\section{Input frequency and the prosodic structure of truncated forms}

The last analysis turns to the hypothesis that prosodic structure frequency affects the prosodic profile of truncated forms. If there is such an effect, there should be a tendency for truncated forms to have the prosodic structures frequent in the input. To test this prediction, all the truncated forms of trisyllabic targets in the data $(1 ; 5-2 ; 1)$ were examined to see whether they tended toward frequent shorter forms. Tables 13-15 show the probability distribution of output forms for each trisyllabic structure that underwent truncation. For instance, the figures for HHL2 in Table 13 mean that when Aki truncated target words with that structure, it had an $80 \%$ chance to become $\mathrm{HL}$ and a $20 \%$ chance to become $\mathrm{HH}$. This was calculated by dividing the number of lexical items with a particular truncated output type by the number of lexical word types attempted in that category. When there was more than one output form for a given word, the count was split between the output types proportionally to the token frequency (e.g., if 7 out of 10 of the truncated outputs for /bánana/ (LLL1) had the shape LL and the other three HL, then the score for /bánana/ was 0.7 point to LL and 0.3 point to HL). The mean score reported near the bottom indicates the overall probability of any truncated form to be of that shape. The token and type frequencies in the maternal input are also shown as probabilities out of 1.0. 


\section{Table 13}

Distribution of truncated forms for trisyllabic targets (Aki)

\begin{tabular}{|c|c|c|c|c|c|c|c|}
\hline \multirow[b]{2}{*}{ Target } & & \multicolumn{6}{|c|}{ Truncated form } \\
\hline & & $L$ & $H$ & $L L$ & $L H$ & $H L$ & $H H$ \\
\hline LLL0 & & 1.00 & & & & & \\
\hline LLL1 & & & 0.33 & 0.33 & & 0.33 & \\
\hline LLL2 & & & 1.00 & & & & \\
\hline LLH0 & & & 1.00 & & & & \\
\hline LLH2 & & & & & & & 1.00 \\
\hline LLH3 & & & & & & & 1.00 \\
\hline LHL2 & & & & & & 1.00 & \\
\hline HLL1 & & & & 0.50 & & 0.50 & \\
\hline HLH2 & & & & 1.00 & & & \\
\hline HLH3 & & & & & & 1.00 & \\
\hline HHLC & & & 1.00 & & & & \\
\hline HHL2 & & & & & & 0.80 & 0.20 \\
\hline $\mathrm{HHH}$ & & & & & & & 1.00 \\
\hline $\mathrm{HHH}$ & & & & & & & 1.00 \\
\hline Mean & & 0.07 & 0.24 & 0.13 & 0.00 & 0.26 & 0.30 \\
\hline \multirow[t]{2}{*}{ Input } & Type & 0.01 & 0.01 & 0.17 & 0.08 & 0.14 & 0.05 \\
\hline & Token & 0.01 & 0.09 & 0.36 & 0.09 & 0.09 & 0.04 \\
\hline
\end{tabular}

\section{Table 14}

Distribution of truncated forms for trisyllabic targets (Ryo)

\begin{tabular}{|c|c|c|c|c|c|c|}
\hline \multirow[b]{2}{*}{ Target } & \multicolumn{6}{|c|}{ Truncated form } \\
\hline & $L$ & $H$ & $L L$ & $L H$ & $H L$ & $H H$ \\
\hline LLL0 & 0.10 & & 0.90 & & & \\
\hline LLL1 & & & 1.00 & & & \\
\hline LLH0 & & 1.00 & & & & \\
\hline LLH2 & & & & 0.50 & & 0.50 \\
\hline LHL0 & & 1.00 & & & & \\
\hline LHL2 & & & 0.50 & & 0.50 & \\
\hline HHL2 & & & & & 1.00 & \\
\hline ННН0 & & & & & & 1.00 \\
\hline $\mathrm{HHH} 2$ & & & & & & 1.00 \\
\hline
\end{tabular}




\begin{tabular}{|c|c|c|c|c|c|c|c|}
\hline HLH0 & & & & & 1.00 & & \\
\hline HLL2 & & & & & & & 1.00 \\
\hline Mean & & 0.01 & 0.18 & 0.22 & 0.14 & 0.14 & 0.32 \\
\hline Input & Type & 0.01 & 0.08 & 0.26 & 0.07 & 0.12 & 0.04 \\
\hline & Token & 0.01 & 0.15 & 0.34 & 0.04 & 0.13 & 0.10 \\
\hline
\end{tabular}

\section{Table 15}

Distribution of truncated forms for trisyllabic targets (Tai)

\begin{tabular}{|c|c|c|c|c|c|c|c|}
\hline \multirow[b]{2}{*}{ Target } & & \multicolumn{6}{|c|}{ Truncated form } \\
\hline & & $L$ & $H$ & $L L$ & $L H$ & $H L$ & $H H$ \\
\hline LLL0 & & 0.20 & & 0.60 & & 0.20 & \\
\hline LLL1 & & & & 0.79 & & 0.21 & \\
\hline LLL2 & & & & 0.75 & & 0.25 & \\
\hline LLH0 & & & 0.67 & & 0.33 & & \\
\hline LLH1 & & & & & 1.00 & & \\
\hline LLH2 & & & 1.00 & & & & \\
\hline LLH3 & & & & & 1.00 & & \\
\hline LHL0 & & & & & & & 1.00 \\
\hline LHL2 & & & & 0.31 & & 0.69 & \\
\hline LHL3 & & & & & & 1.00 & \\
\hline HLL0 & & & & 0.50 & & & 0.50 \\
\hline HLH0 & & & & & & 1.00 & \\
\hline HLH2 & & & & & 0.50 & 0.50 & \\
\hline HHL1 & & & 1.00 & & & & \\
\hline HHL2 & & & & 0.06 & & 0.63 & 0.31 \\
\hline HHL3 & & & & & & 1.00 & \\
\hline HНH1 & & & & & & & 1.00 \\
\hline НHН2 & & & 0.13 & & & 0.13 & 0.75 \\
\hline Mean & & 0.01 & 0.15 & 0.17 & 0.16 & 0.31 & 0.20 \\
\hline \multirow[t]{2}{*}{ Input } & Type & 0.01 & 0.03 & 0.13 & 0.06 & 0.11 & 0.06 \\
\hline & Token & 0.01 & 0.10 & 0.24 & 0.05 & 0.17 & 0.10 \\
\hline
\end{tabular}

Apart from the low rate for $\mathrm{L}$ both in the input and the output, there is no consistent correspondence between the probability of truncated form and input frequency (either type or token). The most frequent input form with one or two syllables, LL, is not the most common destination of truncation as a whole. By far the least frequent disyllabic form in all children, $\mathrm{LH}$, has a truncated form probability 
as high as HL in Ryo's data, and as high as LL in Tai's data. These results indicate that, when truncated, trisyllabic targets do not have a systematic tendency to have prosodic structures frequent in the input. Rather, many of the patterns in the data can be explained by several generalizations that follow from the structural description of the target word: (a) the tendency to omit one rather than more syllables (except in the case of unaccented words); (b) the tendency to retain the weight of the target syllables; and (c) the tendency to retain the accented syllable (see Ota, 1998, 2003; also see Kehoe, 1999/2000, Lohuis-Weber \& Zonneveld, 1996, for similar generalizations made for other child languages). ${ }^{8}$ Together, these tendencies account for the most commonly observed truncation patterns, illustrated below with relevant examples.

(6) $\mathrm{LLL1} \rightarrow \mathrm{LL}$
a./tómato/ $\rightarrow$ [oma]
'tomato' (Aki, 2;0.12)
b./bánana/ $\rightarrow$ [bana], [nana]
'banana' (Ryo, 1;10.5)
c. /bánana/ $\rightarrow$ [mana]
'banana' (Tai, 1;7.15)

(7) LHL2 $\rightarrow$ HL
a./torákku/ $\rightarrow$ [takıu]
'truck'
(Aki, 2;1.24)
b./tatáita/ $\rightarrow$ [taita]
'hit-PAST'
(Ryo, 2;1.25)
c. /zidó:ja/ $\rightarrow \quad$ [do: $[\mathrm{a}]$
'car'
(Tai, 1;8.28)

(8) $\mathrm{HHL} 2 \rightarrow \mathrm{HL}$
a. $/ k^{\mathrm{j}} \mathrm{u}^{\mathrm{j}}{ }^{\mathrm{j}} \mathrm{u}: \mathrm{fa} / \quad \rightarrow$ [Sintfa], [tfurtfur]
'ambulance' (Aki, 1;11.29, 2;1;24)
b. / Jo:bó:fa/ $\rightarrow$ [bo: $\left.\int \mathrm{a}\right]$
'fire engine' (Ryo, 2;0.25)
c. /hambárgu/ $\rightarrow$ [bargu]
'hamburger steak' (Tai, 1;9.17)

(9) $\mathrm{HHH} 2 \rightarrow \mathrm{HH}$
a. / Sinkánsen/ $\rightarrow$ [Sinki: $]$ 'bullet train' (Aki, 2;1.3)
b. /ampámman/ $\rightarrow$ [am:an] '(name of cartoon character)' (Tai, 1;5.20)
c. /hambárga:/ $\rightarrow$ [am:a:] 'hamburger' (Tai, 1;5.27, 1;6)

These generalizations can be extended to quadrisyllabic targets. Most importantly, $88.9 \%$ to $92.3 \%$ of accented quadrisyllabic targets truncated to trisyllabic targets. The tendency to retain the accented syllable and the weight of syllable are illustrated in the following examples.

8 The second generalization supports the claim that Japanese children develop sensitivity to moraic structures quite early in the development (Ota, 2003). Bimoraicity of a syllable in the target may be retained even when the segmental composition is altered (cf. 9a, 10a). 
(10)

\section{LLLH4 $\rightarrow$ LLH}
a. /omofirói/ $\rightarrow$ [omofoi] 'funny-NONPAST'
(Tai, $1 ; 10.14)$
b. /utaretái/ $\rightarrow$ [uretai] 'hit-PASSIVE-DESITERATIVE'
(Tai, 1;11.20)
c. /ikimasén/ $\rightarrow$ [itesen] 'go-NEG-FORMAL'
(Ryo, 2;0.28)

(11) $\mathrm{LLLH} 2 \rightarrow \mathrm{LLH}$

$$
\text { /ari'gato:/ } \rightarrow \text { [arigo:] 'thank you' (Ryo, 2;1.25) }
$$

(12) LLHL3 $\rightarrow$ LHL

/majone'zzu/ $\rightarrow$ [mane:zu] 'mayonnaise' (Tai, 1;11.20)

(13) $\mathrm{HLHH} 3 \rightarrow \mathrm{HLH}$

\section{/tankuróśi:/ $\rightarrow$ [tankuri:] 'tank-lorry' (Tai, 1;8.13)}

These results run counter to the prediction that longer words truncate to prosodic structures that are frequent in the input since disyllabic words are the most frequent word size in child-directed Japanese. Truncation of quadrisyllabic targets to trisyllabic outputs rather than mono- or disyllabic outputs has been reported in other languages including child English, for example, alligator ['hegedə] (Kehoe, 1999/2000), child Spanish, for example, /arbolito/ [bo'lito] 'little tree' (Gennari \& Demuth, 1997) and child Dutch, for example, /helikoptər/ [hejikəpt] 'helicopter' (Lohuis-Weber $\&$ Zonneveld, 1996). That this pattern of truncation is attested across languages indicates that early words are not always subjected to a templatic size restriction - a point already made by several researchers (e.g., Kehoe, 1999/2000; Lohuis-Weber \& Zonneveld, 1996; Taelman, 2004). Of course, these results do not eliminate the possibility that an earlier stage exists where all long targets are truncated to the most frequent prosodic structures, such as LL. This issue will be discussed below.

\section{Discussion}

The purpose of this study was to address three questions concerning the relationship between input frequency and word truncation in early Japanese production: (a) whether target words are less likely to truncate when they have a prosodic structure more frequent in the input, (b) whether target words are less likely to truncate when they are lexical items that are more frequent in the input, and (c) whether truncated forms tend to take the shape of frequent shorter forms. The first hypothesis was not supported by the analysis. No negative correlation was found between truncation rate and prosodic word type when word length was controlled. The second hypothesis was supported by the data, which revealed a significant negative correlation between truncation rate and target word frequency. The third hypothesis was refuted by the finding that trisyllabic and quadrisyllabic targets did not truncate to frequent disyllabic forms.

There are different ways to interpret the outcome of the structural frequency analysis. First, the failure in finding a correlation between truncation rate and frequency of prosodic word structure may be due to methodological problems. Target 
words were classified into prosodic structure types based on the three parameters, number of syllables, syllable weight and accent, as these are known to influence early word truncation. However, the factorial combination of the three variables may have sliced up the structural space into categories that do not necessarily reflect the learner's phonological analysis. At the same time, there may be phonological properties other than these three, such as segmental structures, that are more relevant to the grouping of words into categories relevant to truncation. The detailed classification of prosodic structures also generated prosodic types represented by one or few target words. This may have resulted in poor estimates of the central tendencies in structure-specific truncation rates. Second, there is a possibility that frequency effects mediated by the phonological structure of the target words interact with markedness effects. The hypothesis tested here did not assume the existence of markedness effects that are independent of input probability distribution. ${ }^{9}$ However, certain structures, such as $\mathrm{LH}$, may be inherently more susceptible to truncation regardless of how frequent they might be in the input. Such effects could have masked the influence of input frequency. Stites et al. (2004) also point out that frequency-markedness interaction can be subjected to individual differences, whereby some children show weaker structural frequency effects with respect to markedness effects, and vice versa. In future analysis, then, putative markedness effects need to be factored out. Thirdly, the analysis might have missed an earlier stage during which truncation rates are in fact related to input frequencies of prosodic word structures. Given the generally low rates of truncation in the analyzed portion of the data, it is plausible that these Japanese-speaking children had already grown out of a stage when prosodic structure frequency could play a visible role in word truncation. Unfortunately, this could not be tested due to sparseness of relevant data in the earlier files of the corpora.

The correlation found between the frequency of target words and their truncation rates also leaves some room for interpretation, as such a correlation does not necessarily mean that children become better at producing certain words because of their frequent input. It is possible that the correlation reflects the opposite causal relation, for example, mothers' tendency to repeat words they know their children are capable of producing in a targetlike fashion. Nevertheless, the result is consistent with the hypothesis that at least one way in which input distribution can influence children's word production is through the frequency of target words. It also corroborates the finding that word frequency has a positive effect on children's segmental production (Gierut, Morrisette, \& Champion, 1999). This raises the possibility that what appears to be a frequency effect on a particular phonological structure may actually be a combined frequency effect on a group of lexical items. For instance, one of the empirical issues brought up in the introduction was the individual differences in words that tend to have higher truncation rates, such as LH0 for some Japanese-speaking children and LH2 for others. In addition to the possibility that LH is a marked structure, these differences may arise from different input frequencies of individual words that have structures such as LH0 and LH2. Some children may encounter a

9 Whether phonological markedness can be disentangled from distribution probability remains an empirical question (see Hume, in press, and Zamuner, Gerken, \& Hammond, 2005, for related discussion). 
few LH0 words that happen to be frequent in the input. These words become more accessible to the child, which reduces their truncation rate, consequently lowering the overall rate of truncation for the LH0 category, but only as an epiphenomenon. It may also be that such a change in the child's phonological ability spearheaded by a few lexical items eventually spreads to similar words through lexical diffusion (Gierut, Morrisette, \& Champion, 1999; Morrisette, 1999; Storkel \& Gierut, 2002) or through the construction of word templates, that is, sets of preferred motor plans (Vihman \& Velleman, 2000).

It is worth noting that lexical items that lead changes in phonological development are not always older words that have been in the child's productive lexicon longer (Menn \& Matthei, 1992). Thus, words acquired earlier do not necessarily have a shorter period of truncation than words acquired later (Johnson, Lewis, \& Hogan, 1997), and truncation of early-acquired words may persist even after similar-shaped words become available for adult-like production (see e.g. the case of "residual" reduction of the word $d a d d y$ ([daj]) in Moskowitz's (1970) data). This suggests that lexical frequency cannot be equated with the type of lexical familiarity associated with the age of acquisition, although how exactly input statistics ultimately affect children's word production remains to be investigated.

The results of the last analysis showed that the distribution of the truncated forms had little to do with the frequency of those structures and more to do with the tendencies to preserve, to the extent possible, certain aspects of the target prosodic structure such as syllable count, syllable weight and accent. By definition, syllable count is compromised in truncated outputs, but the majority of forms lose no more than one syllable. Of course there may be a developmental dimension to this, and quadrisyllabic targets may tend to truncate down to one or two syllables in the early stages. But the analysis in this study indicates that even if there is such a phase which could reflect structural frequency effects on the shape of truncation, it does not last long, whereas lexical frequency continues to have an influence on the types of words that undergo truncation. On the whole the evidence suggests that input frequency has a much clearer connection to what truncates than how it truncates.

Let us now evaluate the implications of this study for the issue of variation in truncation. The crosslinguistic import of the Japanese data is consistent with the observation made in previous studies: the input frequency of prosodic word types, at least in terms of word length, does seem to affect the timing of when longer production becomes possible. The distribution of prosodic word types in Japanese is different from English-type languages (in that it has a much higher proportion of multisyllabic words) and from Spanish-type languages (in that it has many more disyllables than longer words). Given this pattern of input, the truncation pattern for trisyllabic words in Japanese is predicted to be somewhere between these two types of languages, and overall this prediction is borne out. In the present study, the overall truncation rate for trisyllabic targets is $20 \%$ or less for all two of the three children by $2 ; 0$. Reliable production of trisyllabic target words in Japanese therefore takes place much earlier than that typically reported for English- or German-speaking children, and is somewhat later than that reported for Spanish-speaking children (see Lléo, 2002; Lléo \& Demuth, 1999). 
The lexical frequency effect confirmed in Analysis 3 provides one straightforward explanation for the individual variability in truncation rate across words that share the same prosodic structures. Independently of their prosodic structure, frequent target words are more accurately produced, and as individual children have different lexicons, truncation rates for words with similar prosodic structures can vary depending on which words the child knows and produces in spontaneous speech.

The analytical outcomes of this study highlight the importance of taking lexical factors into account when making generalizations about children's early phonological system. In studying early phonological phenomena such as truncation, there is a tendency to discount differences across lexical items in favor of the general pattern shown by structure-based analysis. The finding that word frequency can influence truncation rate shows that this practice may not only overlook the contribution of lexical factors but also risk the danger of confounding them with structural effects (see Zamuner et al., 2004, for a similar note of caution). In more careful analyses of early word production, therefore, word frequency needs to be controlled for. Sparse spontaneous speech corpora such as the one used in this study have some inherent limitations in this respect, and it is hoped that more systematic probing will be achieved in future research through other methodological means.

\section{References}

ALLEN, G. D., \& HAWKINS, S. (1980). Phonological rhythm: Definition and development. In G. H. Yeni-Komshian, J. F. Kavanagh \& C. A. Ferguson (Eds.), Child Phonology, 1, (pp. 227-256). New York: Academic Press.

ASLIN, R. N., SAFFRAN, J. R., \& NEWPORT, E. L. (1998). Computation of conditional probability statistics by human infants. Psychological Science,, ,, $321-324$.

BECKMAN, M. E., \& EDWARDS, J. (2000). Lexical frequency effects on young children's imitative productions. In M. Broe \& J. Pierrehumbert (Eds.), Papers in laboratory phonology V (pp. 208-218). Cambridge University Press.

BECKMAN, M. E., YONEYAMA, K., \& EDWARDS, J. (2003). Language-specific and languageuniversal aspects of lingual obstruent productions in Japanese-acquiring children. Journal of the Phonetic Society of Japan, 7, 18-28.

BLASDELL, R., \& JENSEN, P. (1970). Stress and word position as determinants of imitation in first language learners. Journal of Speech and Hearing Research, 13, 193-202.

DEMUTH, K. (1995). Markedness and the development of prosodic structure. In J. Beckman (Ed.), Proceedings of the North East Linguistics Society (pp.13-25). Amherst, MA: Graduate Linguistic Student Association.

DEMUTH, K. (1996). The prosodic structure of early words. In J. Morgan \& K. Demuth (Eds.), Signal to syntax: Bootstrapping from speech to grammar in early acquisition (pp. 171-184). Mahwah, NJ: Lawrence Erlbaum.

DEMUTH, K., \& FEE, E. J. (1995). Minimal words in early phonological development. Unpublished manuscript, Brown University, Providence, Rhode Island, and Dalhousie University, Halifax, Nova Scotia.

DEMUTH, K., \& JOHNSON, M. (2003). Truncation to subminimal words in early French. Canadian Journal of Linguistics, 48, 211-241.

ECHOLS, C. (1993). A perceptually-based model of children's earliest productions. $\underline{\text { Cognition, }}$ 34, 137-195.

ECHOLS, C., \& NEWPORT, E. (1992). The role of stress and position in determining first words. Language Acquisition, $\underline{\mathbf{2}}, \mathbf{1 8 9 - 2 2 0 .}$ 
FEE, E. J. (1995). Two strategies in the acquisition of syllable and word structure. In E. Clark (Ed.), Proceedings of the 27th annual Child Language Research Forum (pp. 29-38). Stanford, CA: CSLI.

FERGUSON, C. A., \& FARWELL, C. B. (1975). Words and sounds in early language acquisition. Language, 51, 419-439.

FIKKERT, P. (1994). On the acquisition of prosodic structure. Dordrecht: Holland Institute of Generative Linguistics.

FUJIWARA, Y. (1977). Yooji no gengo hyoogen nooryoku no hattatsu. Hiroshima: Bunka Hyoronsha.

GENNARI, S., \& DEMUTH, K. (1997). Syllable omission in Spanish. In E. M. Hughes \& A. Greenhill (Eds.), Proceedings of the 21st Annual Boston University Conference on Language Development, vol.1 (pp.182-193). Somerville, MA: Cascadilla Press.

GERKEN, L. (1994). A metrical template account of children's weak syllable omissions from multisyllabic words. Journal of Child Language, 21, 565-584.

GIERUT, J. A., MORRISETTE, M. L. \& CHAMPION, A. H. (1999). Lexical constraints in phonological acquisition. Journal of Child Language, 26, 261-294.

HIRAYAMA, T. (1985). Nihon akusento chizu. Tokyo: NHK.

HUME, E. (in press). Deconstructing markedness: A predictability-based approach. To appear in Proceedings of the Berkeley Linguistic Society, 30.

INGRAM, D. (1988). The acquisition of word-initial [v]. Language and Speech, 31, 77-85.

ITÔ, J. (1990). Prosodic minimality in Japanese. In M. Ziolkowski, M. Noske \& K. Deaton (Eds.), Papers from the 26th meeting of the Chicago Linguistic Society (pp. 213-239). Chicago, IL: Chicago Linguistic Society.

ITÔ, J., \& MESTER, A. (1989). Feature predictability and underspecification: Palatal prosody in Japanese mimetics. Language, 65, 258-293.

ITÔ, J., \& MESTER, A. (1993). Licensed segments and safe paths. Canadian Journal of Linguistics, 38, 197-213.

JOHNSON, J. S., LEWIS, L. B., \& HOGAN, J. (1997). A production limitation in syllable number: A longitudinal study of one child's early vocabulary. Journal of Child Language, 24, 327-349.

KAWAKAMI, M., \& ITO, T. (1999). Yooji no tango koshoo ni okeru hiryuuchoosei no shutsugen to hatsuwa tan'i no kakutoku. Tokushukyooikugaku kenkyuu, 37, 23-30.

KEHOE, M. (1999/2000). Truncation without shape constraints: The late stages of prosodic acquisition. Language Acquisition, 8, 23-67.

KEHOE, M., \& LLEÓ, C. (2003). A phonological analysis of schwa in German first language acquisition. Canadian Journal of Linguistics, 48, 289-327.

KEHOE, M., \& STOEL-GAMMON, C. (1997). The acquisition of prosodic structure: An investigation of current accounts of children's prosodic development. Language, 73, 113-144.

LEVELT, C. C., SHILLER, N. O., \& LEVELT, W. J. (1999/2000). The acquisition of syllable types. Language Acquisition, 8, 237-264.

LEVELT, C. C., \& van de VIJVER, R. (2004). Syllable types in crosslinguistic and developmental grammars. In R. Kager, J. Pater, \& W. Zonneveld, (Eds.), Fixing priorities: Constraints in phonological acquisition. Cambridge: Cambridge University Press.

LLEÓ, C. (2001). The interface of phonology and morphology: The emergence of the article in the early acquisition of Spanish and German. In J. Weissenborn \& B. Höhle (Eds.), Approaches to bootstrapping: Phonological, syntactic and neurophysiological aspects of early language acquisition (pp. 23-44). Amsterdam: John Benjamins.

LLEÓ, C. (2002). The role of markedness in the acquisition of complex prosodc structures by German-Spanish bilinguals. International Journal of Bilingualism, 6, 291-313.

LLEÓ, C., \& DEMUTH, K. (1999). Prosodic constraints on the emergence of grammatical morphemes: Crosslinguistic evidence from Germanic and Romance languages. In A. Greenhill, H. Littlefield, \& C. Tano (Eds.), Proceedings of the 23rd Annual Boston University Conference on Language Development (pp.407-418). Somerville, MA: Cascadilla Press. 
LOHUIS-WEBER, H., \& ZONNEVELD, W. (1996). Phonological acquisition and Dutch word prosody. Language Acquisition, 5, 245-283.

MACKEN, M. A. (1979). Developmental reorganization of phonology: A hierarchy of basic units of acquisition. Lingua, 49, 11-49.

MacWHINNEY, B. (2000). The CHILDES Project: Tools for analyzing talk. 3rd ed. Mahwah, NJ: Lawrence Erlbaum.

McCARTHY, J., \& PRINCE, A. (1995). Prosodic morphology. In J. Goldsmith (Ed.), The handbook of phonological theory (pp.318-366). Oxford: Basil Blackwell.

MENN, L., \& MATTHEI, E. (1992). The "two-lexicon" account of child phonology: Looking back, looking ahead. In C. A. Ferguson, L. Menn, \& C. Stoel-Gammon (Eds.), Phonological development: Models, research, implications (pp.211-247). Parkton, MD: York Press.

MESTER, A. (1990). Patterns of truncation. Linguistic Inquiry, 21, 478-485.

MIYATA, S. (1992). Wh-Questions of the third kind: The strange use of wa-questions in Japanese children, Bulletin of Aichi Shukutoku Junior College, 31, 151-155.

MIYATA, S. (1995). The Aki corpus. Longitudinal speech data of a Japanese boy aged 1.6-2.12. Bulletin of Aichi Shukutoku Junior College, 34, 183-191.

MIYATA, S. (2000). The Tai corpus: Longitudinal speech data of a Japanese boy aged 1;5.20 3;1.1 Bulletin of Aichi Shukutoku Junior College, 39, 77-85.

MIYATA, S., \& NAKA, N. (1998). Wakachigaki gaidorain WAKACHI98 v.1.1. Educational Psychology Forum Report No. FR-98-003. The Japanese Association of Educational Psychology.

MORRISETTE, M. L. (1999). Lexical characteristics of sound change. Clinical Linguistics and Phonetics, 13, 219-238.

MOSKOWITZ, A. I. (1970). The two-year-old stage in the acquisition of English phonology. Language, 46, 426-441.

MUNSON, B. (2001). Phonological pattern frequency and speech production in adults and children. Journal of Speech, Language, and Hearing Research, 44, 778-792.

NOJI, J. (1974). Yoojiki no gengo seikatsu no jittai. Hiroshima: Bunka Hyoronsha.

OSHIMA-TAKANE, Y., \& MacWHINNEY, B., (Eds.). (1998). CHILDES manual for Japanese. Montreal: McGill University and Nagoya: Chukyo University.

OTA, M. (1998). Minimality constraints and the prosodic structure of child Japanese. In D. Silva (Ed.), Japanese/Korean linguistics, 8, (pp.331-344). Stanford, CA: CSLI.

OTA, M. (2003). The development of prosodic structure in early words. Amsterdam: John Benjamins.

PATER, J. (1997). Minimal violation and phonological development. Language Acquisition, 6, $201-253$.

POSER, W. (1990). Evidence for foot structure in Japanese. Language, 66, 78-105.

PYE, C. (1992). The acquisition of K'iche Maya. In D. Slobin (Ed.), The crosslinguistic study of language acquisition, vol. 3 (pp. 221 -308). Hillsdale, NJ: Lawrence Erlbaum.

PYE, C., INGRAM, D., \& LIST, H. (1987). A comparison of initial consonant acquisition in English and Quiche. In K. E. Nelson \& A. van Kleeck (Eds.), Children's language, Vol. 6 (pp. 175-190). Hillsdale, NJ: Lawrence Erlbaum.

ROARK, B., \& DEMUTH, K. (2000). Prosodic constraints and the learner's environment: A corpus study. In S. C. Howell, S. A. Fish \& T. Keith-Lucas (Eds.), Proceedings of the 24th Annual Boston University Conference on Language Development (pp. 597-608). Somerville, MA: Cascadilla Press.

SAVINAINEN-MAKKONEN, T. (2000). Learning long words-A typological perspective. Language and Speech, 43, 205-225.

STITES, J., DEMUTH, K., \& KIRK, C. (2004). Markedness versus frequency effects in coda acquisition. In A. Brugos, L. Micciulla, \& C. E. Smith (Eds.), Proceedings of the 28th Annual Boston University Conference on Language Development (pp. 565-576). Somerville, MA: Cascadilla Press. 
STOEL-GAMMON, C. (1998). Sounds and words in early language acquisition: The relationship between lexical and phonological development. In R. Paul (Ed.), Exploring the speechlanguage connection (pp. 25-52). Baltimore: Paul H. Brookes Publishing Co.

STORKEL, H. L., \& GIERUT, J. A. (2002). Lexical influences on interword variation. In B. Skarabela, S. Fish \& A. H. J. Do (Eds.), Proceedings of the $26^{\text {th }}$ Annual Boston University Conference on Language Development (pp.665-676). Somerville, MA: Cascadilla Press.

SUGITO, M. (1997). Nihon zenkoku no onsei shuushuu. In M. Sugito (Ed.), Shohoogen no akusento to intoneeshon (pp. 3-20). Tokyo: Sanseido.

TAELMAN, H. (2004). Syllable omissions and additions in Dutch child language. An inquiry into the function of rhythm and the link with innate grammar. Doctoral dissertation. University of Antwerp: Antwerp.

TAELMAN, H., \& GILLIS, S. (2002). Variation and consistency in children's truncation patterns. In J. Costa \& M. J. Freitas (Eds.), Proceedings of the GALA 2001 Conference on Language Acquisition (pp. 263-270). Lisbon: Associacào Portuguesa de Linguistica.

TERAO, Y. (1995). Nihongo no tame no UNIBET. In Y. Oshima-Takane \& B. MacWhinney (Eds.), CHILDES manual for Japanese (pp.97-100). Montreal: McGill University.

TSUCHIDA, A. (2001). Japanese vowel devoicing: Cases of consecutive devoicing environments. Journal of East Asian Linguistics, 10, 225-245.

VANCE, T. (1987). An introduction to Japanese phonology. Albany, NY: State University of New York Press.

VIHMAN, M. M. (1991). Ontogeny of phonetic gestures: Speech production. In I. G. Mattingly \& M. Studdert-Kennedy (Eds.), Modularity and motor theory of speech perception (pp. 69-84). Hillsdale, NJ: Lawrence Erlbaum.

VIHMAN, M. M., \& VELLEMAN, S. (2000). Phonetics and the origins of phonology. In N. Burton-Roberts, P. Carr \& G. Docherty (Eds.), Phonological knowledge: Conceptual and empirical issues (pp. 305-339). Oxford: Oxford University Press.

WIJNEN, F., KRIKHAAR, E., \& den OS, E. (1994). The (non)realization of unstressed elements in children's utterances: A rhythmic constraint? Journal of Child Language, 21, 59-83.

ZAMUNER, T. S., GERKEN, L., \& HAMMOND, M. (2004). Phonotactic probabilities in young children's speech production. Journal of Child Language, 31, 515-536.

ZAMUNER, T. S., GERKEN, L., \& HAMMOND, M. (2005). The acquisition of phonology based on input: A closer look at the relation of cross-linguistic and child language data. Lingua, 115, $1403-1426$.

ZIPF, G. K. (1935). The psychobiology of language. Boston, MA: Houghton Mifflin. 


\section{Appendix}

Aki's truncation rates $(1 ; 11-2 ; 1)$

\begin{tabular}{lcccccc} 
& \multicolumn{2}{c}{ Attempted } & \multicolumn{2}{c}{ Truncated } & Maternal input frequency \\
\cline { 2 - 7 } $\begin{array}{l}\text { Prosodic } \\
\text { structure }\end{array}$ & $\begin{array}{l}\text { Word } \\
\text { types }\end{array}$ & $\begin{array}{c}\text { Total } \\
\text { tokens }\end{array}$ & Mean (\%) & $S D$ & Type (\%) & Token (\%) \\
\hline LL0 & 6 & 124 & 2.2 & 5.4 & 1.6 & 5.5 \\
LL1 & 5 & 66 & 2.7 & 6.1 & 5.1 & 5.6 \\
LL2 & 5 & 37 & 7.3 & 10.1 & 5.1 & 6.0 \\
LH2 & 1 & 5 & 0.0 & -- & 3.1 & 2.4 \\
HL0 & 5 & 39 & 0.0 & 0.0 & 1.8 & 1.7 \\
HL1 & 9 & 88 & 1.2 & 3.7 & 5.1 & 3.9 \\
HL2 & 4 & 62 & 10.4 & 8.4 & 2.1 & 3.3 \\
HH0 & 2 & 13 & 0.0 & 0.0 & 2.0 & 1.2 \\
HH1 & 3 & 68 & 5.3 & 5.3 & 1.8 & 1.5 \\
HH2 & 1 & 21 & 4.8 & -- & 0.9 & 1.6 \\
HLH2 & 1 & 12 & 100.0 & -- & 0.4 & 0.2 \\
HHH1 & 1 & 9 & 55.6 & -- & 0.3 & 0.2 \\
HHH2 & 1 & 38 & 5.3 & -- & 0.3 & 1.0 \\
LLLHL4 & 1 & 6 & 100.0 & -- & 0.2 & 0.1 \\
\hline
\end{tabular}

Ryo's truncation rates $(1 ; 11-2 ; 1)$

\begin{tabular}{lcccccc} 
& \multicolumn{2}{c}{ Attempted } & \multicolumn{2}{c}{ Truncated } & Maternal input frequency \\
\cline { 2 - 7 } $\begin{array}{l}\text { Prosodic } \\
\text { structure }\end{array}$ & $\begin{array}{l}\text { Word } \\
\text { types }\end{array}$ & $\begin{array}{c}\text { Total } \\
\text { tokens }\end{array}$ & Mean (\%) & SD & Type (\%) & Token (\%) \\
\hline LL0 & 4 & 124 & 0.4 & 0.9 & 2.1 & 7.1 \\
LL1 & 7 & 66 & 0.0 & 0.0 & 5.9 & 12.1 \\
LL2 & 3 & 37 & 0.0 & 0.0 & 3.7 & 4.1 \\
LH0 & 1 & 12 & 0.0 & -- & 1.6 & 1.3 \\
LH1 & 1 & 11 & 0.0 & -- & 1.3 & 0.5 \\
LH2 & 4 & 69 & 13.6 & 18.9 & 3.2 & 1.9 \\
HL0 & 3 & 57 & 4.8 & 8.3 & 1.7 & 3.0 \\
HL1 & 7 & 176 & 9.0 & 22.5 & 6.7 & 4.0 \\
HL2 & 3 & 121 & 6.1 & 5.6 & 1.5 & 2.0 \\
HH0 & 1 & 5 & 0.0 & -- & 1.6 & 0.9
\end{tabular}




\begin{tabular}{lrrrrrr} 
HH1 & 5 & 89 & 0.3 & 5.6 & 2.0 & 5.7 \\
HH2 & 1 & 15 & 0.0 & -- & 0.8 & 0.5 \\
LLL0 & 2 & 13 & 14.3 & 20.2 & 2.0 & 1.0 \\
LLL1 & 2 & 21 & 30.0 & 42.4 & 2.5 & 1.0 \\
LLL2 & 3 & 35 & 0.0 & 0.0 & 3.7 & 2.1 \\
LLH0 & 1 & 11 & 0.0 & -- & 0.9 & 0.2 \\
LLH3 & 1 & 7 & 0.0 & -- & 2.8 & 1.1 \\
LHL0 & 1 & 18 & 38.9 & -- & 0.1 & 0.2 \\
LHL2 & 1 & 7 & 0.0 & -- & 2.9 & 2.7 \\
HLL2 & 1 & 27 & 3.7 & -- & 1.1 & 0.3 \\
HLH2 & 1 & 15 & 6.7 & -- & 0.4 & 0.3 \\
HHL2 & 1 & 50 & 12.0 & -- & 0.3 & 0.5 \\
HHH0 & 1 & 7 & 14.3 & -- & 0.1 & 0.1 \\
HHH2 & 1 & 34 & 0.0 & -- & 0.3 & 0.6 \\
LLLL2 & 1 & 7 & 14.3 & -- & 1.5 & 0.5 \\
LLHL1 & 1 & 6 & 16.7 & -- & 0.5 & 0.2 \\
LHLH2 & 1 & 15 & 13.3 & -- & 0.3 & 0.1 \\
LLLHL2 & 1 & 6 & 33.3 & -- & 0.4 & 0.5 \\
\hline
\end{tabular}

\section{Tai's truncation rates $(1 ; 5-1 ; 7)$}

\begin{tabular}{|c|c|c|c|c|c|c|}
\hline \multirow[b]{2}{*}{$\begin{array}{l}\text { Prosodic } \\
\text { structure }\end{array}$} & \multicolumn{2}{|c|}{ Attempted } & \multicolumn{2}{|c|}{ Truncated } & \multicolumn{2}{|c|}{ Maternal input frequ } \\
\hline & $\begin{array}{l}\text { Word } \\
\text { types }\end{array}$ & $\begin{array}{c}\text { Total } \\
\text { tokens }\end{array}$ & Mean (\%) & $S D$ & Type (\%) & Token ( \\
\hline LL0 & 6 & 477 & 4.8 & 8.3 & 2.3 & 5.2 \\
\hline LL1 & 5 & 135 & 0.2 & 0.5 & 4.5 & 5.0 \\
\hline LL2 & 2 & 13 & 0.0 & -- & 3.0 & 4.5 \\
\hline LH0 & 1 & 20 & 100.0 & -- & 1.0 & 0.5 \\
\hline LH2 & 3 & 131 & 7.1 & 9.7 & 3.0 & 2.1 \\
\hline HLO & 5 & 60 & 1.5 & 3.4 & 2.0 & 1.7 \\
\hline HL1 & 14 & 432 & 1.0 & 2.2 & 4.7 & 5.7 \\
\hline HL2 & 4 & 269 & 0.4 & 0.7 & 1.7 & 3.0 \\
\hline HH0 & 7 & 148 & 0.7 & 1.8 & 2.3 & 1.5 \\
\hline HH1 & 9 & 125 & 0.7 & 2.2 & 1.7 & 3.8 \\
\hline $\mathrm{HH} 2$ & 3 & 25 & 2.8 & 4.8 & 0.8 & 0.4 \\
\hline LLL0 & 1 & 19 & 0.0 & -- & 2.3 & 0.7 \\
\hline
\end{tabular}




\begin{tabular}{lrrrcrl} 
LLL1 & 3 & 48 & 52.1 & 47.0 & 6.0 & 1.9 \\
LLL2 & 1 & 5 & 40.0 & -- & 2.7 & 0.7 \\
LLL3 & 2 & 11 & 0.0 & 0.0 & 3.0 & 1.2 \\
LLH0 & 1 & 7 & 42.9 & -- & 0.8 & 0.4 \\
LLH2 & 2 & 23 & 0.0 & 0.0 & 1.4 & 0.3 \\
LHH2 & 1 & 9 & 0.0 & -- & 0.5 & 0.3 \\
HLL2 & 1 & 7 & 0.0 & -- & 0.5 & 0.1 \\
HLH2 & 1 & 9 & 100.0 & -- & 0.3 & 0.1 \\
HHH1 & 1 & 7 & 14.3 & -- & 0.2 & 0.8 \\
HHH2 & 2 & 15 & 83.3 & 23.6 & 0.2 & 0.2 \\
LLLH1 & 1 & 11 & 0.0 & -- & 0.5 & 0.5 \\
\hline
\end{tabular}

\section{Tai's truncation rates $(1 ; 8-1 ; 10)$}

\begin{tabular}{lcccccc} 
& \multicolumn{2}{c}{ Attempted } & \multicolumn{2}{c}{ Truncated } & Maternal input frequenc. \\
\cline { 2 - 7 } Prosodic & Word & Total & Mean (\%) & $S D$ & Type (\%) & Token (\%) \\
structure & types & tokens & & & & \\
\hline LL0 & 6 & 958 & 0.3 & 0.7 & 2.3 & 5.2 \\
LL1 & 10 & 211 & 0.7 & 2.2 & 4.5 & 5.0 \\
LL2 & 4 & 43 & 0.0 & 0.0 & 3.0 & 4.5 \\
LH0 & 3 & 82 & 0.0 & 0.0 & 1.0 & 0.5 \\
LH2 & 3 & 83 & 0.0 & 0.0 & 3.0 & 2.1 \\
HL0 & 5 & 92 & 0.8 & 1.9 & 2.0 & 1.7 \\
HL1 & 22 & 481 & 0.2 & 0.7 & 4.7 & 5.7 \\
HL2 & 8 & 387 & 0.4 & 0.7 & 1.7 & 3.0 \\
HH0 & 6 & 91 & 1.0 & 2.4 & 2.3 & 1.5 \\
HH1 & 4 & 69 & 0.0 & 0.0 & 1.7 & 3.8 \\
HH2 & 2 & 37 & 0.0 & 0.0 & 0.8 & 0.4 \\
LLL1 & 3 & 18 & 6.7 & 11.5 & 6.0 & 1.9 \\
LLL2 & 1 & 10 & 0.0 & -- & 2.7 & 0.7 \\
LLL3 & 2 & 23 & 9.6 & 4.1 & 3.0 & 1.2 \\
LLH2 & 1 & 23 & 0.0 & -- & 1.4 & 0.3 \\
LLH3 & 7 & 50 & 14.3 & 37.8 & 2.0 & 0.6 \\
LHL0 & 2 & 30 & 0.0 & 0.0 & 0.5 & 0.1 \\
LHL2 & 1 & 5 & 60.0 & -- & 2.0 & 1.6 \\
LHL3 & 1 & 10 & 0.0 & -- & 1.2 & 0.3
\end{tabular}




\begin{tabular}{lrrrrrr} 
HLL0 & 2 & 54 & 0.0 & 0.0 & 0.6 & 0.1 \\
HLL1 & 3 & 20 & 4.2 & 7.2 & 0.5 & 0.3 \\
HLL2 & 1 & 6 & 0.0 & -- & 0.5 & 0.1 \\
HLH0 & 1 & 11 & 18.2 & -- & 0.1 & 0.0 \\
HLH1 & 2 & 20 & 0.0 & 0.0 & 0.4 & 0.1 \\
HHL1 & 1 & 46 & 6.5 & -- & 0.7 & 0.1 \\
HHL2 & 4 & 39 & 12.5 & 17.7 & 0.5 & 0.1 \\
HHH1 & 3 & 62 & 1.4 & 2.5 & 0.2 & 0.8 \\
HHH2 & 1 & 8 & 0.0 & -- & 0.2 & 0.2 \\
LLLL0 & 1 & 5 & 80.0 & -- & 1.0 & 0.2 \\
LLLL1 & 1 & 14 & 0.0 & -- & 0.2 & 0.3 \\
LLLL3 & 1 & 31 & 0.0 & -- & 1.4 & 0.2 \\
LLLH1 & 1 & 5 & 0.0 & -- & 0.5 & 0.5 \\
LLHL1 & 1 & 14 & 0.0 & -- & 0.8 & 0.3 \\
HLHL1 & 1 & 9 & 0.0 & -- & 0.1 & 0.1 \\
LLLHL2 & 1 & 14 & 21.4 & -- & 0.1 & 0.1 \\
LLHHL3 & 1 & 7 & 57.1 & -- & 0.1 & 0.0 \\
LHLLLL5 & 1 & 5 & 100.0 & -- & 0.1 & 0.0 \\
\hline
\end{tabular}

